\title{
Recent advances and future prospects of iron oxide nanoparticles in biomedicine and diagnostics
}

\author{
N. V. Srikanth Vallabani ${ }^{1} \cdot$ Sanjay Singh ${ }^{1}$ (1)
}

Received: 31 March 2018 / Accepted: 7 May 2018 / Published online: 1 June 2018

(c) The Author(s) 2018

\begin{abstract}
Superparamagnetic iron oxide nanoparticles (SPIONs) are considered as chemically inert materials and, therefore, being extensively applied in the areas of imaging, targeting, drug delivery and biosensors. Their unique properties such as low toxicity, biocompatibility, potent magnetic and catalytic behavior and superior role in multifunctional modalities have epitomized them as an appropriate candidate for biomedical applications. Recent developments in the area of materials science have enabled the facile synthesis of Iron oxide nanoparticles (IONPs) offering easy tuning of surface properties and surface functionalization with desired biomolecules. Such developments have enabled IONPs to be easily accommodated in nanocomposite platform or devices. Additionally, the tag of biocompatible material has realized their potential in myriad applications of nanomedicines including imaging modalities, sensing, and therapeutics. Further, IONPs enzyme mimetic activity pronounced their role as nanozymes in detecting biomolecules like glucose, and cholesterol etc. Hence, based on their versatile applications in biomedicine, the present review article focusses on the current trends, developments and future prospects of IONPs in MRI, hyperthermia, photothermal therapy, biomolecules detection, chemotherapy, antimicrobial activity and also their role as the multifunctional agent in diagnosis and nanomedicines.
\end{abstract}

Keywords Magnetic resonance imaging $\cdot$ Feraheme $\cdot$ Theranostics $\cdot$ Computed tomography $\cdot$ Cell labeling $\cdot$ Nanozymes . Magnetic separation

\section{Introduction}

IONPs possess unique properties, which are used to display several applications in biomedicine such as diagnostics, imaging, hyperthermia, magnetic separation, cell proliferation, tissue repair and drug delivery. Although nanostructures of iron, cobalt, and nickel are known to exhibit superparamagnetic properties and high magnetic susceptibility, IONPs such as magnetite $\left(\mathrm{Fe}_{3} \mathrm{O}_{4}\right)$, hematite $\left(\alpha-\mathrm{Fe}_{2} \mathrm{O}_{3}\right)$ and maghemite $\left(\gamma-\mathrm{Fe}_{2} \mathrm{O}_{3}\right)$, are the most studied magnetic nanoparticle type. Owing to this property, IONPs display aggregation behavior under the magnetic field, which can be suspended again as a stable suspension after removal of the external magnetic field. In addition, the better colloidal stability, biocompatibility, and persistence magnetic properties

Sanjay Singh

sanjay.singh@ahduni.edu.in

1 Division of Biological and Life Sciences, School of Arts and Sciences, Ahmedabad University Central Campus, Navrangpura, Ahmedabad, Gujarat 380009, India of IONPs make them an excellent candidate for biomedical applications (Huang et al. 2009; Isa Karimzadeh 2017).

$\mathrm{Fe}_{3} \mathrm{O}_{4}$ NPs differ from other IONPs due to the presence of both $\mathrm{Fe}^{2+}$ and $\mathrm{Fe}^{3+}$ combinations, where divalent ions are organized at the octahedral sites and trivalent ions are split across the tetrahedral and octahedral sites. However, $\alpha-\mathrm{Fe}_{2} \mathrm{O}_{3}$ contains $\mathrm{Fe}^{3+}$ ions distributed at their octahedral sites and in case of $\gamma-\mathrm{Fe}_{2} \mathrm{O}_{3}$ (termed oxidized magnetite), $\mathrm{Fe}^{3+}$ cations are distributed in octahedral and tetrahedral sites along with $\mathrm{Fe}^{2+}$ cation vacancies located at octahedral sites (Wu et al. 2015b). Due to their feasible polymorphism and their electron hopping nature, these IONPs were classified as potential candidates in both biological and technical applications. In recent years, to enhance the use of IONPs in advanced applications/technologies NPs are altered by the creation of active layers supported by polymers, inorganic metal/metal oxides or bioactive molecules (Gupta and Gupta 2005). The surface engineering of IONPs can be achieved by several methods through layering a coating material over the iron oxide core, to form core-shell structure or the NPs are dispersed in a matrix to form the beads (Gupta et al. 2007). 
In addition, a Janus structure can be formed with one-half of IONPs and the rest with functional material, further, IONPs are embedded between two functional materials to form a shell-core-shell structure (Wu et al. 2015b).

Several methods like thermal decomposition, co-precipitation, sol-gel, microemulsion, hydro-thermal, sonochemical, microwave, electrochemical and biosynthesis were evolved to synthesize IONPs (Huber 2005; Wu et al. 2015b). However, the relation between size, shape, and magnetism in IONPs plays a crucial role in exhibiting their properties. For instance, $\mathrm{Fe}_{2} \mathrm{O}_{3}$ and $\mathrm{Fe}_{3} \mathrm{O}_{4}$ NPs display different ferrimagnetism at room temperature. Further, IONPs tend to lose their dispersity after long-term due to aggregation of particles and their magnetism gets diminished due to oxidation in air. Thus different approaches are implemented to stabilize the NPs in an inert atmosphere and also to make them water-soluble at physiological $\mathrm{pH}$, for applications in nanomedicine (Wu et al. 2015b).

For biomedical applications and in vivo studies, low toxicity, biocompatibility, biodegradability, long retention time, and magnetism to localize the IONPs at the target play a crucial role (Wu et al. 2015b). In diagnosis IONPs, acts as a probe in magnetic resonance imaging (MRI), Positron emission tomography (PET), near-infrared fluorescence (NIRF) imaging (Ju et al. 2017; Xie et al. 2010) and in biosensors for detection of biomolecules like glucose, proteins, urea, and uric acid (Chen et al. 2012; Wu et al. 2015a; Yu et al. 2009). Comparatively, IONPs gained attention in therapeutic nanomedicine ranging from cancer treatment to antimicrobial activity (Nehra et al. 2018; Patra et al. 2017). In theranostics, IONPs are applied as nano-carriers, for enhancing the drug activity in combination therapy (IONPs and chemotherapeutic drugs) or as hyperthermia agents (Ren et al. 2012). Therefore, in the present review article, we focused on the IONPs applications in the domains of diagnosis and therapeutics.

\section{IONPs as imaging probe}

\section{Role of iron oxide nanoparticles as contrast agent in Magnetic Resonance Imaging}

MRI utilizes gradients of magnetic fields, radio waves and electric fields to elucidate the detailed internal structures of the body. MRI has a wide range of applications in detecting diseases or disorders of brain, heart, liver, blood vessels, and other vital organs. Recent research advancements have produced several excellent magnetic contrast agents such as gadolinium, superparamagnetic iron oxides, ultrasmall $(5-10 \mathrm{~nm})$ superparamagnetic iron oxides, gadolinium doped carbon nanotubes, quantum dots embedded paramagnetic micelles and soft nanoparticles such as liposomes, perfluorocarbon emulsions, etc. (Emily and Waters 2008; Liu et al. 2017). Further, IONPs are prepared in combination with other NPs, proteins or dyes to achieve multiple applications in a single stage, for instance, MRI and immunohistochemical staining of cancer cells was executed using ferrimagnetic H-ferritin (M-HFn) nanoparticles, dual MRI and CT imaging of tumor was simultaneously fulfilled by assembling gold $(\mathrm{Au})$ nanocages, $\mathrm{Fe}_{3} \mathrm{O}_{4}$ NPs and triple functional iron oxide nanoparticles (Fig. 1) with Cy5.5 dye and ${ }^{64} \mathrm{Cu}$-DOTA chelate were developed for MRI, positron emission tomography (PET) and near-infrared fluorescence (NIRF) imaging (Cai et al. 2015; Wang et al. 2016; Xie et al. 2010).

Ferumoxytol (Feraheme) is one of the types of magnetic IONPs approved by the US Food and Drug Administration (FDA) for the treatment of patients suffering from iron deficiency with chronic kidney disease (CKD). It consists of a non-stoichiometric magnetite nanoparticle capped by poly glucose sorbitol carboxymethyl ether. Recently many imaging and therapeutic applications have been performed using ferumoxytol and the results suggest that it can be used in MR imaging with IONP cell labels for in vivo tracking of stem cells and also can be applied for non-invasive monitoring of stem cell therapies in pre-clinical and clinical setting (Castaneda et al. 2011). Moreover, studies delineated

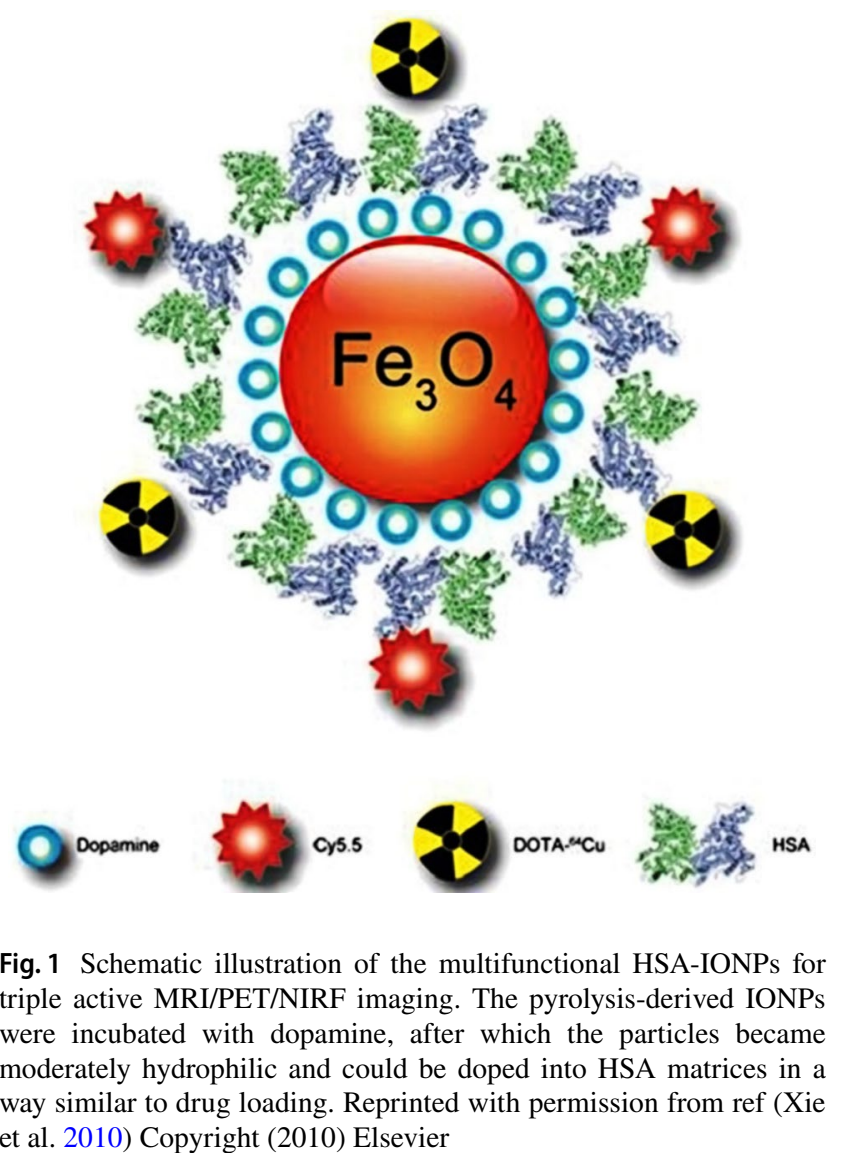
et al. 2010) Copyright (2010) Elsevier 
ferumoxytol-enhanced MRI was more sensitive for detection of early necrosis in tumor cells compared to other contrast agents (Aghighi et al. 2015). Reports also revealed that ferumoxytol gained interest to be used in renal failure patients as an alternative to gadolinium-based contrast agents for vascular MRI (Hope et al. 2015). Furthermore, as the feraheme is taken up by macrophages in liver, lymph nodes and spleen they can be explored for imaging macrophages, tumors, vascular lesions and other organs (Bashir et al. 2015; Vasanawala et al. 2016).

IONPs are a versatile class of material, which can be tuned to exhibit multifunctional applications. In one such attempt, Xie et al. (Xie et al. 2010) have developed dopamine modified IONPs, which was then encapsulated into human serum albumin (HSA) matrices. It was also shown that the HSA coated IONPs can also be labeled with two different dyes, ${ }^{64} \mathrm{Cu}$-DOTA and Cy5.5, to impart multiplexed imaging capability and tested them in a subcutaneous U87MG xenograft mouse model. Results revealed that a tri-modality imaging (including MRI, PET, and NIRF) was very much possible under ex vivo and in vivo experimental condition. HSA coating manifested longer blood circulation time, high extravasation and accumulation in targeted tissues and low uptake in macrophages in the nearby area of tumor.

In the current context, image-guided photothermal therapy (PTT) is being looked as a promising alternative therapeutic modality to the most of the conventional methods. PTT is also expected to have potential to offer a better precision therapy alternative. Owing to the recent developments in material science, it is possible to synthesize the materials of our interest with variable size, shape, and composition. However, producing multicomponent materials with desired dimensions and stability still remains a challenge. Considering this, $\mathrm{Ju}$ et al. have developed a monodispersed composite material ( $\mathrm{Au}-\mathrm{Fe}_{2} \mathrm{C}$ Janus NPs) and used them as multifunctional cancer theranostics. These $12 \mathrm{~nm}$ particles exhibited a broad absorbance pattern under near infrared region, which lead to the generation of significant photothermal effect when irradiated with $808 \mathrm{~nm}$ laser light. This nanocomposite offered excellent optical and magnetic properties, which was found to be a promising method for triple-modal MRI/multispectral photoacoustic tomography (MSOT)/CT imaging both in in vitro and in vivo experimental models. Authors also modified this magnetic nanocomposite with HER2 affibody, which showed higher accumulation and deep tissue penetration in tumors than unconjugated particles (Ju et al. 2017). In another study by Monaco et al. developed a multi-layered nano-system composed of $\mathrm{Fe}_{3} \mathrm{O}_{4}$ NPs, coated with inner silica and outer Au layers. These NPs were entrapped into polymeric micelles and surface was conjugated with folic acid to offer them water solubility and target recognition. This novel nano-system was shown applications in targeting and magnetic resonance-photoacoustic based dual imaging modality. The significance of the complex system lies in having optical properties of gold NPs and a high dielectric constant of silica NPs ensuring strong light absorption capability (Fig. 2). Hence, they were utilized as a bimodal MRI-photoacoustic imaging (PAI) agent for imaging and detection of ovarian cancer (Monaco et al. 2017).

Malignant cells are characterized to have a significantly high rate of metabolism and glucose uptake. Utilizing this mechanism, cancer tissues are visualized under PET, involving high uptake of a radiolabelled glucose analog, [18F]-2-fluoro-2-deoxy-D-glucose (Lindholm et al. 1993). It is reported that the glucose transporter (Glut) proteins are found in the plasma membrane of mammalian cells, which facilitates the transport of glucose in the cytoplasm. Although there are several Glut proteins, however, Glut-1 has been shown to be involved in the high transportation of glucose in cancer cells (Singh 2017). Therefore, Glut proteins are considered as one of the suitable markers to selectively identify the cancer cells/tissues. The conjugation of Glut antibody with IONPs was shown to diagnose hemangioma (a condition in which noncancerous growths of blood vessels occur) through their MRI contrast imaging modality. The study was focussed on the differentiation of infantile hemangioma from vascular malformation, as Glut-1 is only expressed in cells of infant hemangioma (Sohn et al. 2015).

In general, IONPs acts as a probe for negative contrast ( $T_{2}$ contrast agents) due to their superparamagnetic behaviour and large magnetic moment. However, a typical dark signal produced in the $T_{2}$ image can cause difficulty in distinguishing the areas of interest with calcium deposits, bleeding and glioma imaging. To overcome the limitation, Juan et al. synthesized citrate coated IONPs (C-ESION) with excellent positive $\left(\mathrm{T}_{1}\right.$ imaging $)$ and negative contrast

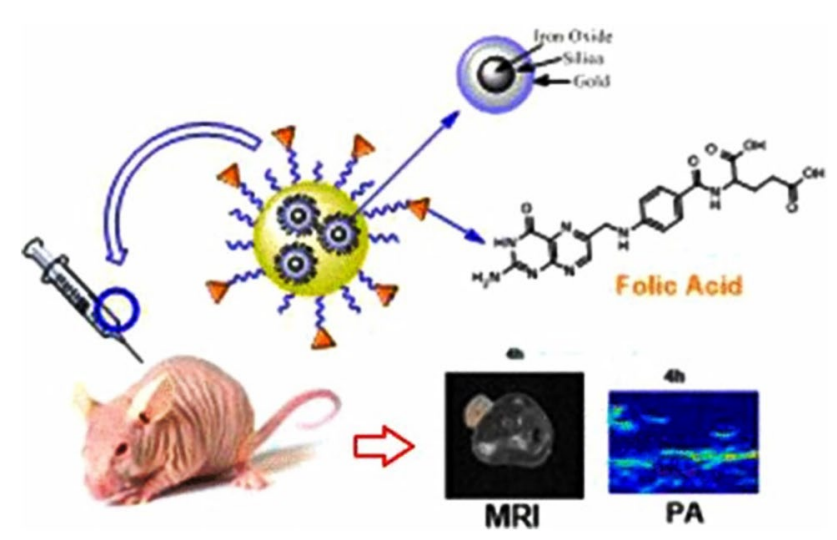

Fig. $2 \mathrm{Fe}_{3} \mathrm{O}_{4}$ NPs coated with inner silica and outer gold layers have been entrapped in polymeric micelles, decorated with folic acid moieties, and tested in vivo for photoacoustic and magnetic resonance imaging detection of ovarian cancer. Reprinted with permission from ref (Monaco et al. 2017) Copyright (2017) American Chemical Society

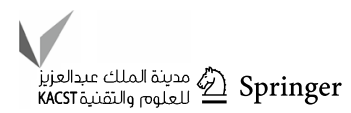


through modulating the composition and coating thickness. In addition, authors demonstrated that the coating chemistry on NPs surface can change their relaxometric properties, which can be manipulated to generate particles with different contrasts. Results explained C-ESION120 displayed $\mathrm{T}_{1}$ weighed contrast and C-ESION140 showed $\mathrm{T}_{2}$ contrast signal characteristics. Hence, the modified coating enabled the maghemite NPs for $\mathrm{T}_{1}$ high-resolution MR angiography and also provided standard $\mathrm{T}_{2}$ contrast to utilizing them for a full range of applications in MRI (Pellico et al. 2017). Further, Ning et al. synthesized Gd-doped and PEG-coated IONPs (PEG-GdIO) having $\mathrm{T}_{1}-\mathrm{T}_{2}$ bimodal contrast ability and demonstrated the simultaneous $\mathrm{T}_{1}-\mathrm{T}_{2}$ contrast imaging in mice bearing glioma. Results revealed that after $1 \mathrm{~h}$ of NPs injection $T_{1}$ and $T_{2}$ weighted images showed brighter and darker contrast compared to pre-injection MR images. Moreover, the contrast enhancement was analyzed by contrast to noise ratio and significant improvement in signals was found for both $T_{1}$ and $T_{2}$ contrast images. Hence, it was concluded that PEG-GdIO NPs can be used as dual contrast agent for brain glioma detection (Xiao et al. 2014). Cha et al. modified $\mathrm{Fe}_{3} \mathrm{O}_{4} \mathrm{NPs}\left(\mathrm{Fe}_{3} \mathrm{O}_{4} @ \mathrm{GCP}-\mathrm{Fe}_{3} \mathrm{O}_{4}\right.$ surface modified with glutathione, cyclodextrin and polymer) through polymer coating composed of $\beta$-cyclodextrin core and poly [2-(dimethylamino) ethyl methacrylate] arms and in association with reduced glutathione (GSH) as a model drug. The designed platform was expected for simultaneous diagnosis and treatment purposes. Authors suggested $\mathrm{Fe}_{3} \mathrm{O}_{4}$ NPs coated with these star polymers exhibited more GSH association compared to linear polymers and showed better stability in serum solutions. Further $\mathrm{Fe}_{3} \mathrm{O}_{4} @ \mathrm{GCP}$ rendered low cytotoxicity and possessed enhanced $\mathrm{T}_{1} \mathrm{MRI}$ characteristics. Results showed significant bright enhancement observed for $\mathrm{T}_{1}$ weighted images of liver visualization suggesting that the modified NPs can be used for diagnosis and treatment of chronic liver diseases (Cha et al. 2017).

\section{Use of iron oxide nanoparticles as contrast agent in computed tomography}

CT is an X-ray based whole body imaging technique that combines series of computer processed X-ray images to construct the cross-sectional images of specific areas. CT is used to diagnose diseases or internal injuries in blood vessels, bones, soft tissues and other parts of the body. Clinically approved CT contrast agents for intravenous injection are iodinated small molecules or barium suspensions. Due to hypersensitive to iodinated contrast and renal impaired patients there is a need for better contrast agents. So, several nanoparticles including metallic, polymeric, liposomes, lipoproteins, micelles, and emulsions have been reported to yield better results as contrast agents for CT imaging (Cormode et al. 2014; Thomas et al. 2013) Carril et al. worked on $6 \mathrm{~nm}$ gold-coated Iron oxide glyco NPs and showed they can be effectively used for multimodal imaging in CT, MRI, and ultrasound (US) as contrast agents. Results explained that the increased gold coating on NPs surface was able to enhance the CT contrast through X-ray attenuation. Moreover, NPs with reduced size, sugar coating and negative surface charge allowed for long circulation time in blood and proved to be biocompatible (Mónica Carril 2014). Additionally, Naha et al. reported the synthesis of a composite consisting of bismuth-iron oxide nanoparticles (BION) with dextran coating. Data revealed that no cytotoxicity was observed in HepG2 (human liver cancer cell line) and BJ5ta (human fibroblast cell line) after $24 \mathrm{~h}$ incubation with NPs. In vivo CT imaging with optimized NPs concentration showed the contrast in heart and blood vessels indicating prolonged circulation half-life. Further, some contrast was observed in liver and spleen suggesting that the non-specific nanoparticle accumulation in these organs. It was concluded that NPs are biocompatible, biodegradable and possess strong X-ray attenuation characteristics, which can be used as a strong contrast agent for dual CT and MRI imaging (Naha et al. 2014). In another attempt, Perlman et al. indicated that IONPs can be used in ultrasonic computed tomography (UCT) for breast imaging. The imaging showed an improvement in contrast to noise ratio and can also serve as a pre-screening platform for disease diagnosis. Moreover, it was suggested that these NPs can be applied for multimodal MRI-ultrasound imaging purposes (Perlman and Azhari 2017). Reguera et al. designed a novel gold-iron oxide-based Janus magnetic-plasmonic NPs as contrast agents for imaging under CT, MRI, PAI, TEM, surface enhanced Raman spectroscopy (SERS) and optical microscopy. These complementary techniques allow obtaining maximum information and can serve as a multipurpose biomedical platform (Reguera et al. 2017).

\section{Iron oxide nanoparticles in positron emission tomographic imaging}

PET is a nuclear imaging method that provides whole-body imaging and evaluates tissue and organ functions thus enables quantification and localization of activity. However, it cannot reveal anatomical or morphological imaging. So to achieve advancements in imaging, CT, MRI or US can be combined to form a hybrid system such as PET/CT or PET/ MRI for better resolution and anatomy of cells and tissues (Evertsson et al. 2017). de Rosales et al. reported the synthesis of a novel NPs system through bifunctional chelator dithiocarbamate-bisphosphonate conjugation to ${ }^{64} \mathrm{Cu}$ and dextran coated IONPs for PET and MR imaging. Further, the labeling of clinically available IONPs (Endorem/Feridex) with ${ }^{64} \mathrm{Cu}$-based bifunctional chelator was performed and their dual-modality imaging was demonstrated in vivo in lymph nodes (Torres Martin de Rosales et al. 2011). Nahrendorf et 
al. conjugated a PET tracer ${ }^{64} \mathrm{Cu}$ to dextran coated magneto fluorescent NPs to yield a tri-modality reporter $\left({ }^{64} \mathrm{Cu}-\mathrm{TNP}\right)$ for PET, MRI and fluorescence imaging. The capability of multimodal NPs was applied to detect macrophages in atherosclerotic plaques. Authors hypothesized that the in vivo PET signal correlates well with the inflammatory plaques observed by MRI, fluorescence imaging and flow cytometry (Nahrendorf et al. 2008). Xiaoqiang et al. developed a multifunctional nanocarrier functionalized with tumor targeting ligand, DOX-

conjugated and ${ }^{64} \mathrm{Cu}$ labeled IONPs. The carrier provides targeted anticancer drug delivery and PET/MRI-based dual imaging modality of tumors expressing integrin $\alpha_{v} \beta_{3}$. In vitro studies explained cRGD ligand (cyclic arginineglycine-aspartic peptides) conjugated NPs exhibited more cellular uptake and tumor accumulation compared to free NPs shown by quantitative PET imaging and biodistribution analysis (Yang et al. 2011). A similar study was performed by Lee et al. to develop a bifunctional probe for PET and MR imaging. Polyaspartic acid coated IONPs were synthesized and conjugated with a cRGD ligand for integrin targeting and labeled with ${ }^{64} \mathrm{CuDOTA}$ for PET analysis (Lee et al. 2008). Additionally, Chakravarty et al. synthesized ${ }^{69} \mathrm{Ge}-$ labeled metal oxides by mixing IONPs with ${ }^{69} \mathrm{Ge}$ ions. The simple method has an advantage in forming intrinsic radiolabelled NPs without any use of chelators. In addition, these NPs can be used for simultaneous PET and MRI imaging (Chakravarty et al. 2014) (Table 1).

\section{Bio-sensing applications of iron oxide nanoparticles}

\section{Role of Iron oxide nanoparticles as nanozymes}

Recent developments in nanotechnology have also aimed towards the construction of novel enzyme mimetics (nanozymes) exhibiting biological oxidase, peroxidase, catalase, and superoxide dismutase-like activities (Gao et al. 2017; Karim et al. 2018; Lin et al. 2014d; Shah and Singh 2018). Nanozymes are nanomaterials possessing intrinsic biological enzyme-like properties, which offer several advantages over natural enzymes such as high stability and activity at varying conditions of $\mathrm{pH}$ and temperatures, cost effectivity, easy manipulation and multiple applications on a single platform. The shape, size, and composition controlled synthesis of nanomaterials provides easy modulation of their nanozymatic activity, which is one the major limitations with natural enzymes. Various metal and metal oxide-based nanomaterials such as IONPs, Gold, Silver, Copper, and nanosheets of graphene, $\mathrm{MoS}_{2}, \mathrm{WS}_{2}$ are shown to display horseradish peroxidase (HRP)-like activity. These enzyme-mimetic activities are shown to be used for the construction of non-enzymatic biosensors to test the levels/concentrations of glucose, glutathione, cholesterol, $\mathrm{H}_{2} \mathrm{O}_{2}$, urea, creatinine and biomarkers for cancer diagnosis (Gawande et al. 2016; Lin et al. 2014a, b; Mahato et al. 2018a, b; Vallabani et al. 2017; Wang et al. 2017; Zheng et al. 2011). These biomolecules are well-known biomarkers for several diseases, thus the developed biosensors could be used for the early diagnosis of these diseases. In general, the peroxidase-like activity of these nanozymes is observed at an optimum $\mathrm{pH}$ of 3-5, through the generation of hydroxyl radicals by Fenton reaction. For glucose detection, most of the colorimetric assays follow a two-step procedure. In the first step, glucose gets oxidized in presence of glucose oxidase $(\mathrm{GOx})$ to release $\mathrm{H}_{2} \mathrm{O}_{2}$ at neutral $\mathrm{pH}$. In the second step, the obtained $\mathrm{H}_{2} \mathrm{O}_{2}$ along with HRP or peroxidase mimetics are allowed to oxidize the substrates like 3,3',5,5'-tetramethylbenzidine (TMB), 2,2'-azino-bis(3ethylbenzothiazoline-6-sulphonic acid) (ABTS) and $O$-phenylenediamine (OPD) to form the colorimetric product at acidic $\mathrm{pH}$. Although nanozymes degrade $\mathrm{H}_{2} \mathrm{O}_{2}$ rapidly and follow the oxidation of the products by hydroxyl radicals, still the reaction suffers from several shortcomings such as lower substrate affinity and specificity than natural enzymes. Such events lead to the lower performance of nanozymes, which ultimately faces limited applicability in sensing and biomedicine. Therefore, it becomes necessary to develop novel ways to enhance the catalytic activity of nanozymes. To address this issue, $\mathrm{Yu}$ et al. have studied the impact of citrate, glycine, polylysine, dextran and heparin coating on the peroxidase mimetic MNPs (Yu et al. 2009). They observed that the developed anionic NPs had high affinity towards TMB, whereas cationic NPs showed high affinity for ABTS. Based on the substrate affinity, they were able to detect glucose in the traditional two-step process and suggested that the nanozymatic activity can also be extended to other biomedical applications. Bhagat et al. have developed Gold-core/Cerium oxide-shell NPs exhibiting a multienzyme complex-like activity including catalase, SOD, and peroxidase enzyme-like activities. Kinetic parameter study related to peroxidase activity demonstrated that the core-shell nanozyme activity was comparable to the natural enzyme, horseradish peroxidase (HRP). In addition, authors also explained that oxidation of TMB was carried through electron transfer instead of hydroxyl radical participation. Additionally, the enzyme activity was conserved at a broad range of $\mathrm{pH}(2-11)$ and temperatures (up to $90{ }^{\circ} \mathrm{C}$ ). However, the nanozyme exhibited optimum SOD and catalase activity at neutral $\mathrm{pH}$ and for peroxidase, it was found at acidic pH. Finally, the nanozymatic (peroxidase mimetic) activity was utilized for the detection of glucose in a range from $100 \mu \mathrm{M}$ to $1 \mathrm{mM}$ in a time span of $5 \mathrm{~min}$ and at $\mathrm{pH}$ 4 (Bhagat et al. 2017). Additionally, Wu et al. developed a magnetic core-shell microgel system with immobilized GOx

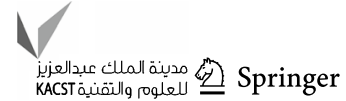




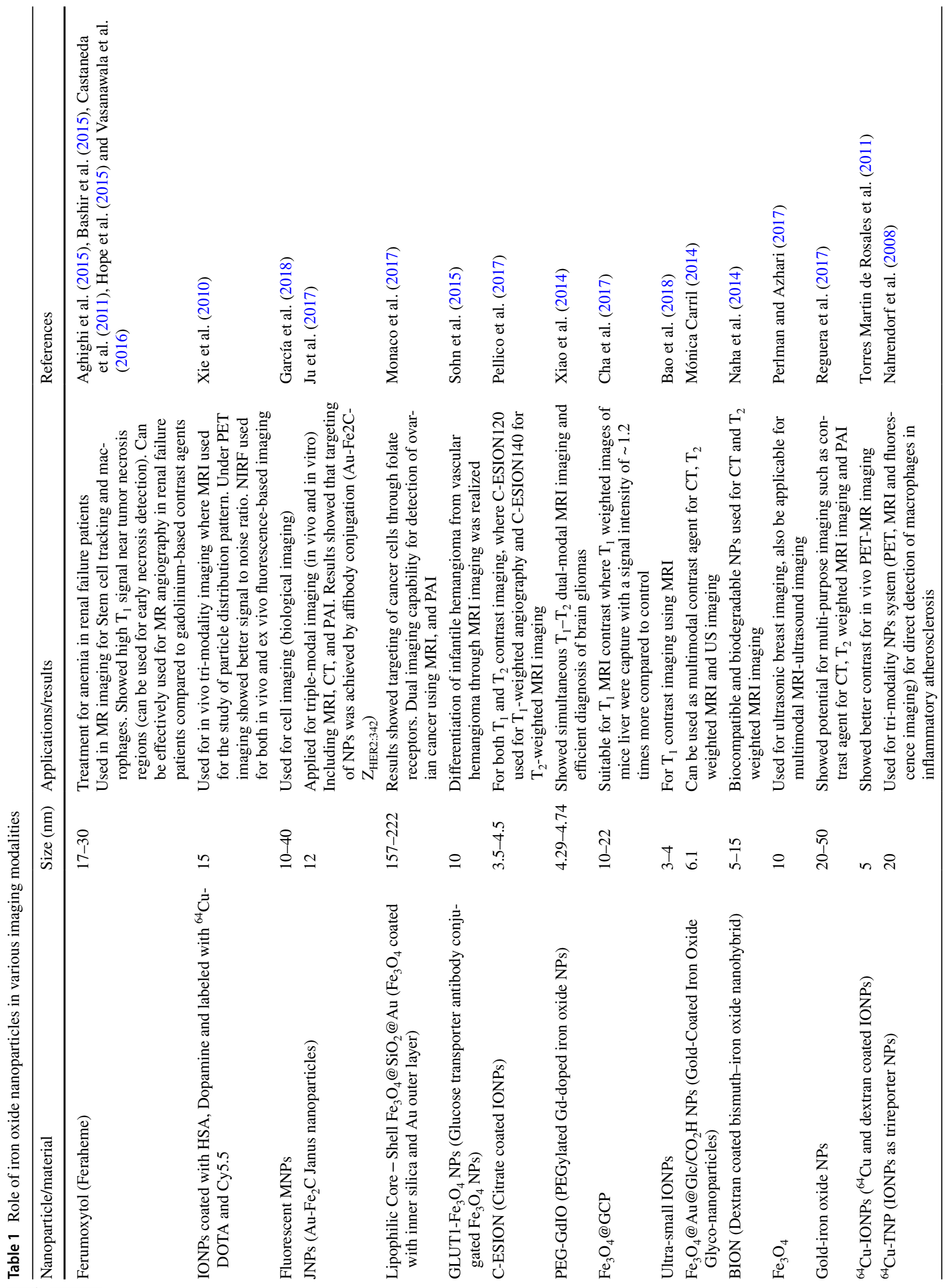


and HRP molecules. Due to co-entrapment of enzymes, they utilized the magnetic microgel for the colorimetric detection of glucose in a single step at pH 5.5 (Fig. 3). Moreover, they suggested that this detection system can also be extended for detecting biomolecules through new oxidase or peroxidase platforms (Wu et al. 2015a).

Composite materials have also been studied for the possible nanozymatic activities. In one such attempt, carbon nanotube/polyaniline-based metal oxide (Fe, Co, Ni) NPs are synthesized to show peroxidase mimetic activity using TMB and phenol/4-aminoantipyrine (4-AAP/phenol) to study the peroxidase-like activity and translated into a colorimetric method for glucose detection (Navvabeh Salarizadeh et al. 2017). Additionally, Vazquez-Gonzalez et al., have shown that NPs composed of the Prussian blue (PB), CuFe, $\mathrm{FeCoFe}$, and $\mathrm{FeCo}$ inorganic clusters mimic the peroxidase activity. They suggested that PBNPs catalyze the oxidation of $\mathrm{NADH}$ by $\mathrm{H}_{2} \mathrm{O}_{2}$ to form $\mathrm{NAD}^{+}$which can be applied for chemical transformations by $\mathrm{NAD}^{+}$dependent enzymes such as ethanol dehydrogenase (Fig. 4). It was also found that the FeCo NPs catalyzed chemiluminescence generation in presence of $\mathrm{H}_{2} \mathrm{O}_{2}$ and luminol and extended this system for effective sensing of glucose (Vazquez-Gonzalez et al. 2017). Recently, bimetallic 2D nanosheets are also reported to act as biological peroxidase enzyme. In this context, Tan et al. synthesized bimetallic nanosheets exhibiting peroxidase-like activity, which can be modulated with the single-stranded DNA (ssDNA). The major attraction of this method was the switchability of peroxidase-like catalytic activity with DNA (Fig. 5). By modulating the enzyme-like activity of these nanosheets they achieved an ultra-sensitive detection of $\mathrm{H}_{2} \mathrm{O}_{2}$ with a range of 2.86-71.43 $\mathrm{nM}$ and comparable detection of glucose with a linear range of $12.86-257.14 \mu \mathrm{M}$ (Tan et al. 2017).

\section{Iron oxide nanoparticles in electrochemical sensing and role of biomolecules in enhancing nanozyme activity}

Unlike enzymatic reactions, nanomaterials exhibit the nonenzymatic way to detect the biomolecules. Since these methods are not constrained by the need of special conditions of $\mathrm{pH}$ and temperature, the process of detection does not get interference with other comparative biomolecules. Baby and Ramaprabhu et al. reported a superparamagnetic nanocomposite composed of $\mathrm{SiO}_{2}$ coated $\mathrm{Fe}_{3} \mathrm{O}_{4}$ NPs dispersed on multiwalled-carbon nano tubes $\left(\mathrm{Fe}_{3} \mathrm{O}_{4} @ \mathrm{SiO}_{2} /\right.$ MWNT) exhibiting enhanced electron transfer ability and biocompatibility. This system was successfully applied to the development of a glucose and cholesterol sensor without any interference from other biomolecules and did not involve any enzyme (Baby and Ramaprabhu 2011). Further, Nor et al. developed a high sensitive biosensor for glucose

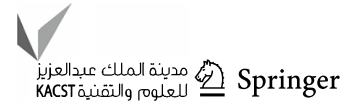


Fig. 3 Synthesised magnetic core-shell microgels for single step colorimetric detection of glucose. Reprinted with permission from ref (Wu et al. 2015a) Copyright (2015) Royal Society of Chemistry

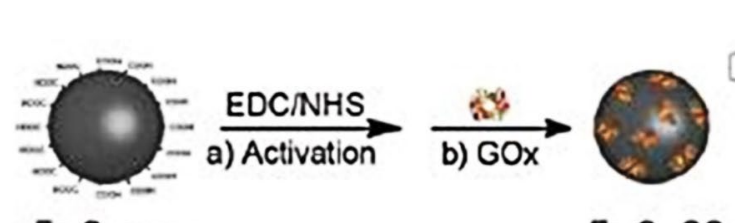

$\mathrm{Fe}_{3} \mathrm{O}_{4}$ core $\mathrm{Fe}_{3} \mathrm{O}_{4} \cdot \mathrm{GOx}$
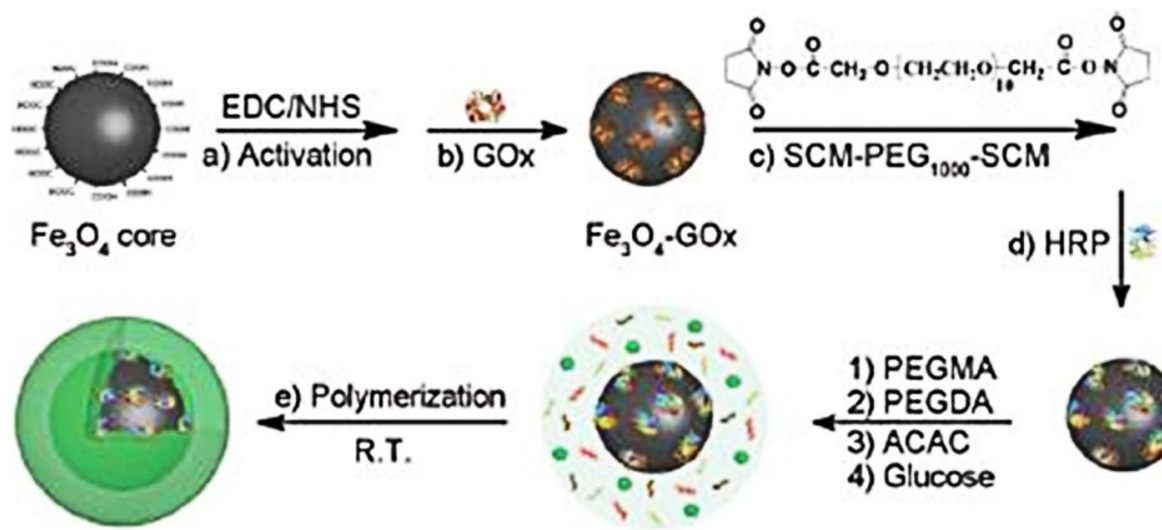

e) Polymerization

R.T.

core-shell microgel

\&5 GOx th HRP

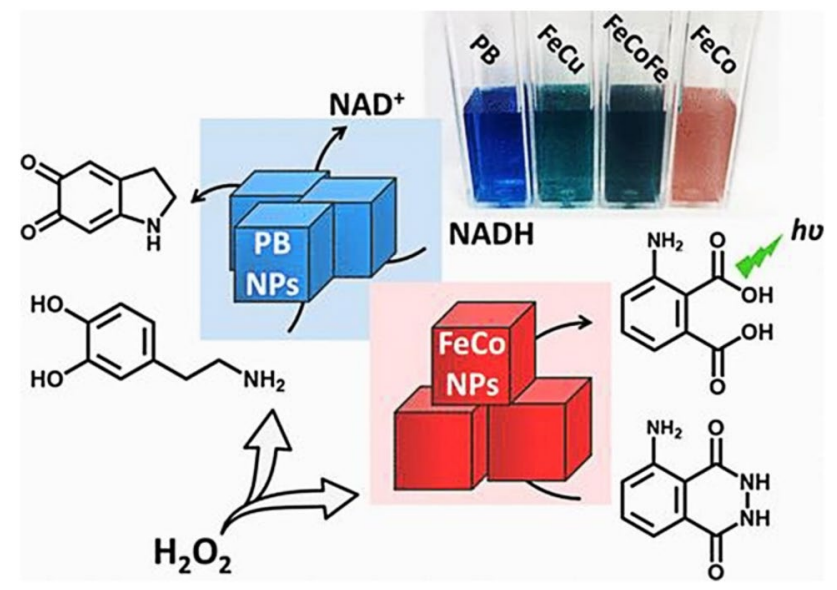

Glucose
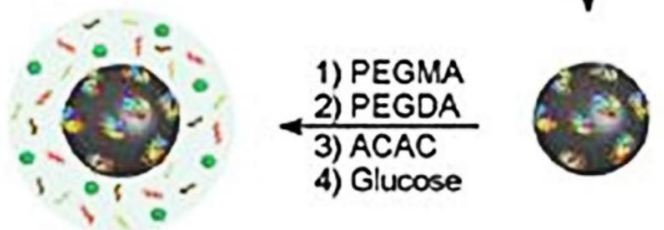

coating solution

$\mathrm{Fe}_{3} \mathrm{O}_{4}-\mathrm{GOX} \cdot \mathrm{HRP}$

PEGDA
Fig. 4 Prussian blue (PB), and the cyanometalate structural analogs, $\mathrm{CuFe}, \mathrm{FeCoFe}$, and $\mathrm{FeCo}$, are examined as inorganic clusters that mimic the functions of peroxidases. Schematic showing PB NPs catalyzed oxidation of NADH by $\mathrm{H}_{2} \mathrm{O}_{2}$ to form $\mathrm{NAD}^{+}$and chemiluminescence generation by the FeCo NPs catalyzed oxidation of luminol by $\mathrm{H}_{2} \mathrm{O}_{2}$. Reprinted with permission from ref (Vazquez-Gonzalez et al. 2017) Copyright (2017) American Chemical Society

detection using Nafion/GOx/IONPs/screen printed carbon electrode (SPCE). The amperometric biosensor exhibited a wide range of glucose detection with a lower limit of $7 \mu \mathrm{M}$ (Nor et al. 2017) (Fig. 6). In the similar concept, Kacar et al. developed an amperometric biosensor for creatine monitoring using $\mathrm{Fe}_{3} \mathrm{O}_{4}$-nanoparticles-modified carbon paste electrodes. The method relies on two enzymatic catalyzed reactions, creatinase, and sarcosine oxidase to generate $\mathrm{H}_{2} \mathrm{O}_{2}$ and finally, the sensor sensitivity depends on the response towards $\mathrm{H}_{2} \mathrm{O}_{2}$ for creatine determination (Kacar et al. 2013). Since the creatine level in the human blood and urine acts as a clinical parameter to monitor muscle damage, this system could be of immense benefit to clinical monitoring of these biomolecules.

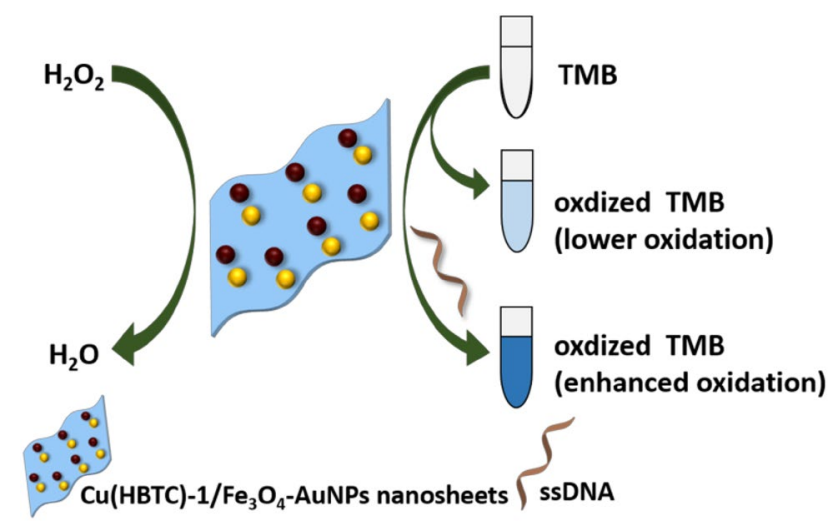

Fig. 5 Schematic illustration of peroxidase-like activity and its controllability regulated by DNA of $\mathrm{Cu}$ (HBTC)-1/Fe3O4-AuNPs nanosheets. Reprinted with permission from ref (Tan et al. 2017) Copyright (2017) Royal Society of Chemistry

Composites of multiwalled-carbon nanotubes doped metal oxide $\mathrm{NPs}\left(\mathrm{NiO}, \mathrm{ZnO}\right.$, and $\left.\mathrm{Fe}_{3} \mathrm{O}_{4}\right)$ are coated on glassy carbon electrode and used for the sensitive detection of serotonin from body fluids such as urine. Serotonin is a wellknown neurotransmitter and neuromodulator which plays a significant role in several biological processes like liver degeneration, endocrine regulation, anxiety, and depression. Hence, the determination of serotonin levels in the blood can assist to diagnose several diseases. Using this material, authors showed the voltammetry-based determination of serotonin, dopamine and ascorbic acid, simultaneously with high signal to noise ratio (Fayemi et al. 2017). Urea is another marker for kidney failure, obstructions in urinary tract, liver failure and other gastrointestinal problems. Ali et al. devised a potentiometric sensor by immobilizing urease enzyme over chitosan conjugated $\mathrm{Fe}_{3} \mathrm{O}_{4} \mathrm{NPs}$ for detecting urea in the range of $0.1-80 \mathrm{mM}$ (Ali et al. 2013). Andrea et al. developed IONPs for the sensitive and direct 


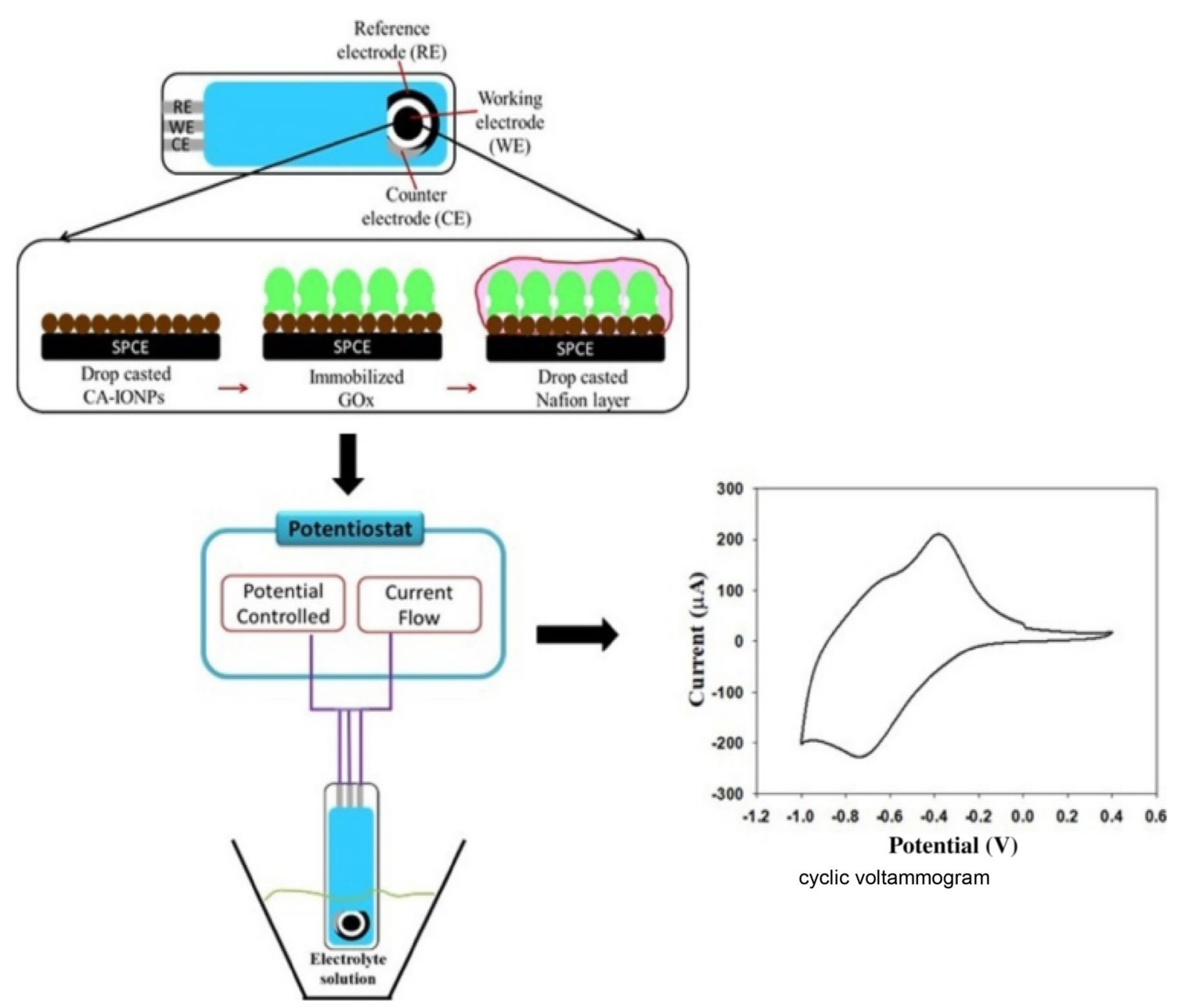

Fig. 6 Schematic illustration of Nafion/GOx/IONPs/SPCE biosensor for electrochemical based detection of glucose. Reprinted with permission from ref (Nor et al. 2017) Copyright (2017) Elsevier

detection of biomolecules from biological samples. The NPs were functionalized with lipopolysaccharides obtained from a Brucella species and detected the presence of Brucella antibodies in serum. Further authors suggested that the method is versatile and NPs can be functionalized with different antigens on the surface, which could be used for easy identification of a variety of analytes from the body fluids (Fornara et al. 2008).

To increase the efficiency of nanozymes and overcome the $\mathrm{pH}$ constraints, synergistic molecules like nucleobases, nucleosides, nucleotides, and DNA are supplemented in the solution or coated on to the surface of NPs. This synergistic effect allows the design of simple and novel sensors for biomolecule detection at the desired $\mathrm{pH}$ (Lin et al. 2014c; Pu et al. 2017; Shah et al. 2015). Thus, to enhance the utility and translate the system into a point-of-care device platform, one-step method of detection is imperative. In this context, Vallabani et al. reported a novel strategy to overcome the limitation of acidic $\mathrm{pH}$ for hydroxyl radical generation and showed that with the use of ATP, IONPs exhibited excellent peroxidase mimetic activity at physiological $\mathrm{pH}$. Moreover, the enzymatic activity was preserved over a wide range of $\mathrm{pH}$ and temperatures in presence of ATP. They utilized the property for single step detection of glucose at $\mathrm{pH} 7.4$ and further extended to detect glucose level in human blood serum (Vallabani et al. 2017). Further to this study, Liang et al. synthesized novel NPs by growing coordinate polymer (CP) shell made of $\mathrm{Fe}^{3+}$ and Adenosine monophosphate (AMP) on $\mathrm{Fe}_{3} \mathrm{O}_{4}$ NPs. CP shell showed an advantage in encapsulating a wide variety of guest molecules like nucleic acids, proteins, fluorophores, and NPs. Authors explained that the shell has enhanced peroxidase-like activity due to $\mathrm{Fe}_{3} \mathrm{O}_{4}$ present in the core and applied this peroxidase nanozyme for glucose bio-sensing. GOx was entrapped in the shell of $\mathrm{Fe}_{3} \mathrm{O}_{4} \mathrm{NPs}$ for glucose detection and monitored with a sensitivity of $1.4 \mu \mathrm{M}$ (Liang et al. 2016). Additionally, Yang et al. reported that adenosine analogs with phosphate groups can enhance the peroxidase-like activity of $\mathrm{Fe}_{3} \mathrm{O}_{4}$

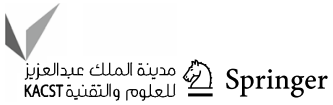


NPs. The improved activity was detected through the oxidation reaction of $\mathrm{H}_{2} \mathrm{O}_{2}$ and amplex ultra-red reagent generating fluorescence. Here the enhanced peroxidase activity of adenosine phosphate analogs showed the activity trend as AMP $>$ ADP $>$ ATP. Based on the protein adsorption on NPs authors also developed a turn-off system for detection of urinary proteins (Yang et al. 2017) (Table 2).

\section{Iron oxide nanoparticles in hyperthermia and photo thermal therapy}

Hyperthermia is a thermal therapy to produce heat near a local or a systemic tumor by energy sources like microwaves, radio waves, ultrasound energy and magnetism. Recently, it has been realized that the conventional methods of cancer treatment suffer from several limitations such as side effects, drug resistance, low availability of drug at the site of action, fast renal clearance, etc. These challenges have allowed researchers to combine the chemotherapy and radiotherapy with hyperthermia. In magnetic hyperthermia,

Table 2 Summary of bio-sensing applications shown by iron oxide nanoparticles

\begin{tabular}{|c|c|c|c|}
\hline Nanoparticle/material & Size $(n m)$ & Applications/results & References \\
\hline Microgel embedded IONP-GOx-HRP & $\sim 200$ & $\begin{array}{l}\text { Exhibited peroxidase like activity. Colorimetric } \\
\text { detection of glucose was carried in a single } \\
\text { step at } \mathrm{pH} 5.5\end{array}$ & Wu et al. (2015a) \\
\hline Prussian blue FeCo NPs & $40-50$ & $\begin{array}{l}\text { PBNPs catalyzed the oxidation of NADH by } \\
\mathrm{H}_{2} \mathrm{O}_{2} \text { to form NAD } \mathrm{NA}^{+} \text {(showed dehydrogenase } \\
\text { like activity). FeCo NPs catalyzed chemilu- } \\
\text { minescence generation in presence of } \mathrm{H}_{2} \mathrm{O}_{2} \\
\text { and luminol (showed Peroxidase like activity). } \\
\text { Glucose detection was performed using FeCo } \\
\text { NPs }\end{array}$ & Vazquez-Gonzalez et al. (2017) \\
\hline $\begin{array}{l}\mathrm{Cu}(\mathrm{HBTC})-1 / \mathrm{Fe}_{3} \mathrm{O}_{4} \text {-AuNPs nanosheets with } \\
\text { ssDNA }\end{array}$ & $5.99 \pm 2.58$ & $\begin{array}{l}\text { Enhanced TMB oxidation was observed in pres- } \\
\text { ence of single stranded DNA. 2D bimetallic } \\
\text { immobilized MOF nanosheets were applied } \\
\text { for detection of } \mathrm{H}_{2} \mathrm{O}_{2}(2.86-71.43 \mathrm{nM} \text { range }) \\
\text { and glucose }(12.86 \text { to } 257.14 \mu \mathrm{M} \text { range })\end{array}$ & Tan et al. (2017) \\
\hline $\begin{array}{r}\mathrm{Fe}_{3} \mathrm{O}_{4} @ \mathrm{SiO}_{2} / \mathrm{MWNT}\left(\mathrm{SiO}_{2} \text { coated } \mathrm{Fe}_{3} \mathrm{O}_{4} \mathrm{NPs}\right. \\
\text { dispersed on Multiwalled-carbon nano tubes) }\end{array}$ & $5-15$ & $\begin{array}{l}\text { Biosensor was applied for detection of glu- } \\
\text { cose }(3 \mu \mathrm{M}-14 \mathrm{mM} \text { range }) \text { and cholesterol } \\
(10 \mu \mathrm{M}-4 \mathrm{mM} \text { range })\end{array}$ & Ramaprabhu (2011) \\
\hline $\begin{array}{l}\mathrm{FeNPs} @ \mathrm{Co}_{3} \mathrm{O}_{4} \text { (IONPs loaded in } \mathrm{Co}_{3} \mathrm{O}_{4} \text { hollow } \\
\text { nanocages) }\end{array}$ & 900 & $\begin{array}{l}\text { Applied for glucose detection with a linear } \\
\text { range of } 0.5-30 \mu \mathrm{M} \text { (limit of detection was } \\
0.05 \mu \mathrm{M})\end{array}$ & Zhao (2018) \\
\hline $\begin{array}{l}\mathrm{Fe}_{3} \mathrm{O}_{4} \text {-nanoparticles-modified carbon paste } \\
\text { electrodes }\end{array}$ & - & $\begin{array}{l}\text { Creatinine was determined with a detection } \\
\text { limit of } 2.0 \times 10^{-7} \mathrm{~mol} \mathrm{~L}^{-1}\end{array}$ & Kacar et al. (2013) \\
\hline Graphene oxide $/ \mathrm{Fe}_{3} \mathrm{O}_{4}$ nanocomposite & 50 & $\begin{array}{l}\text { Biosensor for determination of glucose, with a } \\
\text { range of } 0.5-10 \mathrm{mM}\end{array}$ & Wang (2018) \\
\hline MWCNT doped with Ni, Zn, Fe & $10-50$ & $\begin{array}{l}\text { Serotonin was determined with a detection limit } \\
\text { of } 5.98 \times 10^{-3} \mu \mathrm{M}-62.8 \mu \mathrm{M}\end{array}$ & Fayemi et al. (2017) \\
\hline Chitosan-IONPs with urease & - & Applicable for the detection of urea & Ali (2013) \\
\hline IONPs & 19.5 & $\begin{array}{l}\text { Brucella antibodies detection with a detection } \\
\text { limit of } 0.05 \mu \mathrm{gL}^{-1}\end{array}$ & Fornara et al. (2008) \\
\hline $\mathrm{Fe}_{3} \mathrm{O}_{4} \mathrm{NPs}$ & $13 \pm 3.5$ & $\begin{array}{l}\text { ATP-mediated peroxidase like activity of } \mathrm{Fe}_{3} \mathrm{O}_{4} \\
\text { NPs was observed at pH 7.4. Glucose detec- } \\
\text { tion was carried in a single step at physiologi- } \\
\text { cal pH with a colorimetric detection limit of } \\
50 \mu \mathrm{M}\end{array}$ & Vallabani et al. (2017) \\
\hline $\mathrm{Fe}_{3} \mathrm{O}_{4} \mathrm{NPs}$ with $\mathrm{Fe}^{3+}$ AMP shell & $10-20$ & $\begin{array}{l}\text { Glucose detection was demonstrated with a } \\
\text { detection limit of } 1.4 \mu \mathrm{M}\end{array}$ & Liang et al. (2016) \\
\hline $\mathrm{Fe}_{3} \mathrm{O}_{4} \mathrm{NPs}$ & $\sim 13$ & $\begin{array}{l}\text { Exhibited peroxidase like activity. Can be } \\
\text { applicable as a fluorescent turn-off system for } \\
\text { urinary protein detection }\end{array}$ & Yang et al. (2017) \\
\hline
\end{tabular}


the intratumorally injected IONPs generate heating effect after exposing to an external magnetic field and induce the cell death near the tumor zone (Elham Cheraghipour 2012; Kolosnjaj-Tabi and Wilhelm 2017). Due to poor cellular architecture, cancer cells are very prone to be damaged by the slight increase in the surrounding temperature. Additionally, using hyperthermia strategy, the temperature of the surrounding environment can be increased up to $55-60{ }^{\circ} \mathrm{C}$, which can be very well withstood by normal healthy cells, but not by cancerous cells. Moreover, IONPs can be used to prepare synergistic nano-hybrids tuned for magnetic hyperthermia and photothermia. Photothermal therapy is also possible with the use of other nanoparticles such as anisotropic nanostructures of gold, copper, silver, carbon nanotubes, and

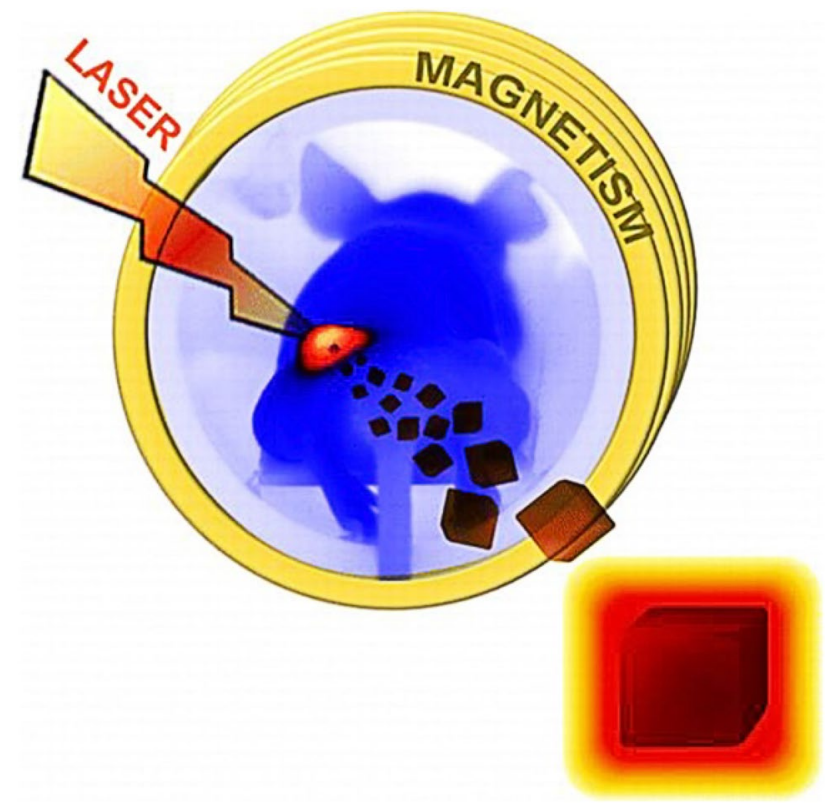

Fig. 7 Dual mode magneto-photo-thermal approach using iron oxide nanocubes for tumor ablation. Reprinted with permission from ref (Espinosa et al. 2016) Copyright (2016) American Chemical Society graphene NPs (Boca et al. 2011; He et al. 2014; Liu et al. 2007; Yavuz et al. 2009). Other morphologies of IONPs are also developed for the photothermal treatment of diseases. Espinosa et al. have used nanocubes of IONPs and showed that when these nanocubes are exposed to the magnetic field as well as near-infrared laser irradiation, two- to five fold amplification in the production of heat was generated than when used magnetic field alone (Fig. 7). Moreover, it was demonstrated the dual-mode stimulation generated efficient heat with low iron concentration $(0.25 \mathrm{M})$ and acceptable laser power irradiation $\left(0.3 \mathrm{~W} / \mathrm{cm}^{2}\right)$ and resulted in a complete cell death and solid tumor suppression (Espinosa et al. 2016). In another attempt, Niu et al. developed a nanosystem comprising of IONPs $\left(\mathrm{Fe}_{3} \mathrm{O}_{4}\right)$, indocyanine green (ICG) and perfluoropentane (PFP) encapsulated in poly (lactidecoglycolide) (PLGA) nanoparticles for NIR induced PTT. The experiments with MCF-7 tumors in mice showed that these multifunctional NPs can enhance tumor ablation upon NIR laser irradiation and can act as a key photothermal agent against the tumors (Niu et al. 2017).

Addressing hyperthermia, Mazario et al. synthesized $10 \mathrm{~nm}$ sized MNPs functionalized with HAS protein and the experimental data revealed these functional materials have the potential role in mediating magnetic hyperthermia by enhancing the temperature of cancer cells. Moreover, authors suggested that heating could induce irreversible damage to cellular proteins and enzymes and thereby the regulation of apoptosis in cells and tissues (Mazario 2017). In a related study, Shen et al. synthesized a magnetic nanocluster for PTT using near-infrared light irradiation. They found that after radiation exposure clusters of $\mathrm{Fe}_{3} \mathrm{O}_{4}$ produced more heating thereby impart significant cytotoxic to A549 cells (human lung carcinoma) compared to bigger sized $\mathrm{Fe}_{3} \mathrm{O}_{4}$ NPs. The mechanistic studies revealed the cell death was caused due to apoptosis, but not necrosis. Further, in vivo studies demonstrated that these clusters can be applied for promising tumor treatment through PTT (Fig. 8) (Shen et al. 2015). Chen et al. have developed highly crystalline IONPs
Fig. 8 Infrared thermal images of phosphate buffered saline (PBS), individual and clustered magnetic $\mathrm{Fe}_{3} \mathrm{O}_{4}$ NPs with the concentration of $100 \mu \mathrm{g} / \mathrm{mL}$ injected in A549 tumor sample under NIR laser irradiation for 0-180 s. Reprinted with permission from ref (Shen et al. 2015) Copyright (2015) Elsevier

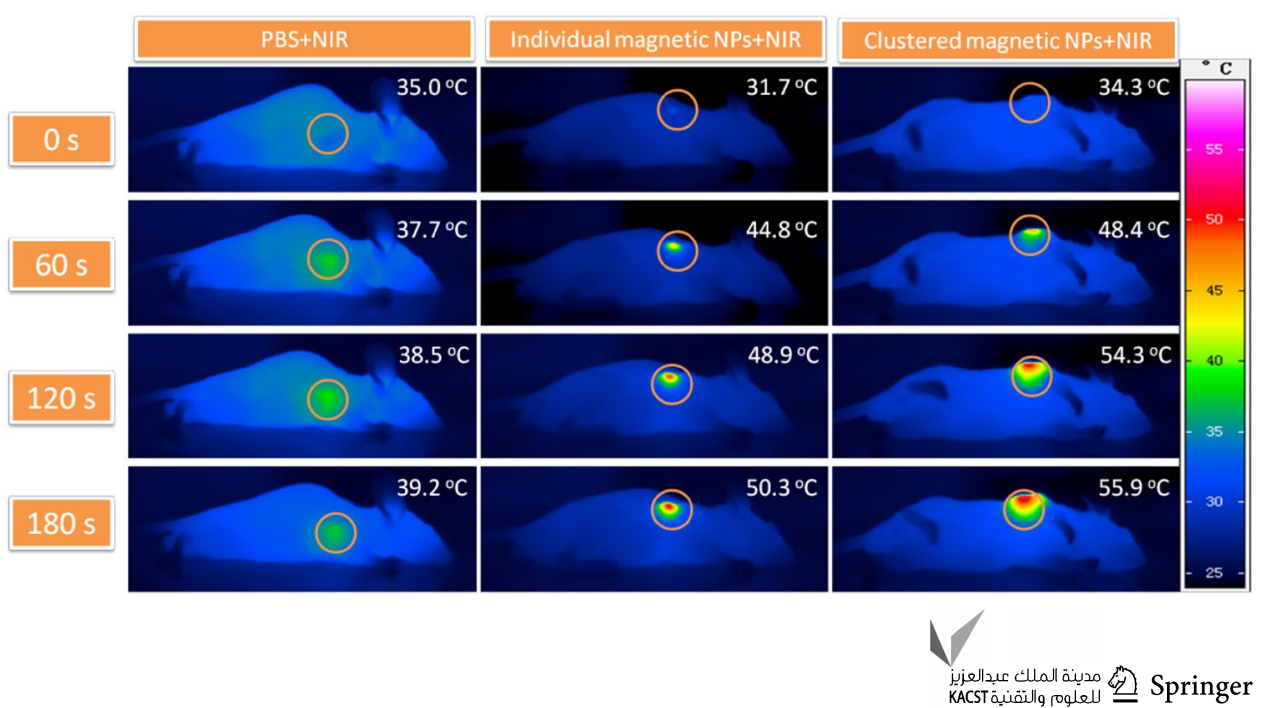


Table 3 Summary of iron oxide based nanoparticles for hyperthermia and photo thermal therapy

\begin{tabular}{|c|c|c|c|}
\hline Nanoparticle/material & Size $(n m)$ & Applications/results & References \\
\hline IONPs (nano-cubes) & 20 & $\begin{array}{l}\text { The dual mode (hyperthermia and PTT) of } \\
\text { treatment amplified the heating effect by } \\
\text { two- to fivefold in comparison with magnetic } \\
\text { stimulation alone. Results showed that in } \\
\text { both in vitro (SKOV3) (ovarian cancer), PC3 } \\
\text { (prostate cancer) and A431 (epidermoid can- } \\
\text { cer) and in vivo (A431 cancerous cells were } \\
\text { injected in nude NMRI mice) complete cell } \\
\text { death was observed after dual mode exposure }\end{array}$ & Espinosa et al. (2016) \\
\hline ICG/ $\mathrm{Fe}_{3} \mathrm{O}_{4}$ loaded PLGA NPs & $\begin{array}{l}\mathrm{Fe}_{3} \mathrm{O}_{4}: 10 \\
\text { Total shell: } \sim 300\end{array}$ & $\begin{array}{l}\text { Used as an efficient treatment by PTT. In vitro } \\
\text { treatment of NPs to MCF-7 breast cancer } \\
\text { cells confirmed the damage to cells and } \\
\text { in vivo studies demonstrated IONPs can be } \\
\text { used as an effective agent for tumor ablation }\end{array}$ & Niu et al. (2017) \\
\hline $\begin{array}{l}\text { Carboxyl-amine functionalized SPIONs based } \\
\text { ferrofluids }\end{array}$ & $\sim 20$ & $\begin{array}{l}\text { In vitro hyperthermia studies revealed tereph- } \\
\text { thalic acid (TA) and aminoterephthalic acid } \\
\text { (ATA) coated SPIONs induced } \sim 90 \% \text { cell } \\
\text { death in breast cancer cells (MCF-7) }\end{array}$ & Kandasamy (2018a) \\
\hline IONPs with HSA & 10 & $\begin{array}{l}\text { Used for thermal therapy. MNPs exhibited a } \\
\text { saturation magnetization of } 63 \mathrm{emu} \mathrm{g}^{-1} \text { at } \\
310 \mathrm{~K} \text { and produced a localized heat in pres- } \\
\text { ence of an alternating magnetic field }\end{array}$ & Mazario (2017) \\
\hline Clustered magnetic $\mathrm{Fe}_{3} \mathrm{O}_{4} \mathrm{NPs}$ & $\begin{array}{l}\mathrm{Fe}_{3} \mathrm{O}_{4}: 15 \\
\text { Clustered } \mathrm{Fe}_{3} \mathrm{O}_{4}: 225\end{array}$ & $\begin{array}{l}\text { Used for PTT. The clustered NPs induced high } \\
\text { temperature and proved to be more cytotoxic } \\
\text { against A549 cells both in vitro and in vivo }\end{array}$ & Shen et al. (2015) \\
\hline SPIONs & $6-10$ & $\begin{array}{l}\text { Hyperthermia based thermotherapy for liver } \\
\text { cancer treatment }\end{array}$ & Kandasamy (2018b) \\
\hline Crystallized IONPs (HCIONPs) & 15 & $\begin{array}{l}\text { Showed effective PTT against SUM-159 tumor- } \\
\text { bearing mice }\end{array}$ & Hongwei Chen (2014) \\
\hline $\begin{array}{l}\text { PEGylated } \mathrm{Fe} @ \mathrm{Fe}_{3} \mathrm{O}_{4} \text { (PEGylated iron/iron } \\
\text { oxide core/shell NPs) }\end{array}$ & $13.4 \pm 0.8$ & $\begin{array}{l}\text { These multifunctional NPs can be applied for } \\
\text { targeting, MRI imaging and PTT }\end{array}$ & Zhou et al. (2014) \\
\hline $\begin{array}{l}\mathrm{Fe}_{3} \mathrm{O}_{4} @ \mathrm{CMCT} \text { (carboxymethyl chitosan stabi- } \\
\text { lized } \mathrm{Fe}_{3} \mathrm{O}_{4} \mathrm{NPs} \text { ) }\end{array}$ & 177 & $\begin{array}{l}\text { Used for PTT. NPs were found accumulated in } \\
\text { the mice tumor region and PTT induced the } \\
\text { increase in temperature up to } \sim 52^{\circ} \mathrm{C}\end{array}$ & Shen et al. (2013) \\
\hline
\end{tabular}

(HCIONPs) coated with the anti-biofouling polymer and used then for photothermal cancer therapy. Results revealed NPs were effectively accumulated in the tumor site of SUM159 tumor-bearing mouse though permeability and retention effect. Further laser irradiation exhibited complete tumor regression within 3 weeks compared to control. Authors suggested that enhanced PTT was due to high crystalline and preferred lattice plane orientations of as prepared HCIONPs compared to normal $\mathrm{Fe}_{3} \mathrm{O}_{4}$ NPs (Hongwei Chen 2014).

Multifunctional IONPs are also designed and have shown better results than their uni-functional counterparts. In this context, PEGylated $\mathrm{Fe} / \mathrm{Fe}_{3} \mathrm{O}_{4}$ NPs have been developed for exhibiting triple functions comprising PTT, targeting, and MRI (Fig. 9). Targeting of cells was achieved with neodymium magnet placed beside a xenograft tumor developed from HeLa cells. The multi-modality allowed the NPs to accumulate in the tumor region, therefore, exhibited intense MRI signal with high photothermal activity (Zhou et al. 2014). PEG coating on nanoparticle surface

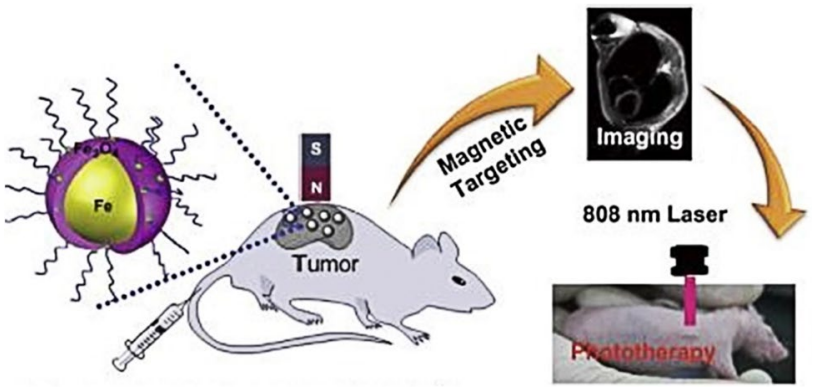

Fig. 9 Schematic illustration of magnetic targeting, MRI and NIR photothermal therapy by multifunctional PEGylated $\mathrm{Fe} / \mathrm{Fe}_{3} \mathrm{O}_{4} \mathrm{NPs}$. Reprinted with permission from ref (Zhou et al. 2014) Copyright (2014) Elsevier

imparts biocompatibility and avoidance to the reticuloendothelial system (RES), which renders the long-term circulation in blood plasma (Larson et al. 2012). Therefore, biocompatible nanomaterials would be an ideal candidate 
for multifunctional applications cell targeting, MRI, sensing, hyperthermia, and PTT. For instance, Shen et al. synthesized a carboxymethyl chitosan coated $\mathrm{Fe}_{3} \mathrm{O}_{4} \mathrm{NPs}$, which exhibited extremely low toxicity and high PTT efficiency. Furthermore, they stated that these NPs platform can be easily fabricated for multiple applications (Shen et al. 2013) (Table 3).

\section{Iron oxide nanoparticles as delivery agents}

\section{Drug delivery applications}

Effective treatment of cancer still remains a major challenge in medicine due to several problems such as drug/multidrug resistance, lack of selective targets for a tumor (El-Boubbou 2018; Vasir and Labhasetwar 2005). Nanotechnology has recently shown some success in effective cancer treatment due to the unusual properties of materials. Among several NP types, IONPs have gained the most attention for applications in nanomedicines due to some of the key attributes, including stable colloidal suspension, resistance to in vivo degradation, presence of large surface area to graft targeting moieties, high payload delivery of drugs, synergistic activity in improving the sensitivity of drugs towards cancer treatment, and reversing the resistance of cancerous cells (Bahrami et al. 2017; Ulbrich et al. 2016).

Traditional methods of cancer treatment include surgery, chemotherapy, radiotherapy, and combinational therapy to alleviate the tumors. However, damage to surrounding cells around a tumor and radio-resistance of cells limits the effectiveness of these conventional therapies. The multifunctional nature of IONPs has been recently exploited for the effective drug delivery for cancer and other disease treatment. Pirayesh Islamian et al. used superparamagnetic mesoporous hydroxyapatite conjugated doxorubicin and deoxy-D-glucose nanocomposites to boost breast cancer chemo and radiotherapy (Pirayesh Islamian et al. 2017). They worked on SKBR3 and T47D breast cancer cell culture models and reported that the cell viability was significantly decreased with combined nanocomposite effect compared to the radiotherapy alone. Mechanistically, they found that targeting of breast cancer cell was achieved with deoxy-D-glucose moiety conjugated on IONPs surface and doxorubicin acted as therapeutic agent, thus the combined effect leads to the improved breast cancer radiotherapy by increased localization of NPs. When investigated further, it was found that the extent of cytotoxicity in tumor cells was much more, with minimum side effects and damage to normal healthy cells. In another strategy, Ye et al suggested that $\mathrm{Fe}_{3} \mathrm{O}_{4}$ NPs can increase the efficacy of cryoablation; a process uses extreme cold conditions to treat cancerous cells. Their data indicated that $\mathrm{Fe}_{3} \mathrm{O}_{4}$ NPs altered intracellular ice formation ability during freezing, recrystallization, and thawing, which leads to the enhanced killing of MCF-7 cells. Therefore, the idea of enhanced ablation using IONPs can be successfully applied to effectively treat tumors in near future (Ye et al. 2017).

Cisplatin is platinum-based anticancer agent reported to treat various types of cancers including lung, testicular, bladder, ovarian, breast, and brain tumors (Dasari and Tchounwou 2014). However, the excess usage of cisplatin is also reported to exhibit various side effects such as kidney damage, neurotoxicity, bone marrow suppression, heart diseases, and allergic reactions (Barabas et al. 2008). It is also well known that the drug resistance shown by tumor cells limits their probability of clinical trial success. To overcome these limitations, platinum drugs are suggested to be encapsulated into polymers or loaded into multifunctional nanocomposites for effective treatment of cancers. In this context, Yan Zhang et al. fabricated a nanocomposite comprising of $\mathrm{Fe}_{3} \mathrm{O}_{4}$ core and polymeric inner shell covered with PEG, and folate groups, and the cisplatin was encapsulated into the inner shell through coordination of amino groups (Yan Zhang 2014). The in vitro release kinetics of cisplatin showed better release at acidic $\mathrm{pH}(\mathrm{pH} \sim 4.5)$ and resulted in a cytotoxic response in HeLa cells through ligand-mediated targeting of folate receptors (overexpressed on HeLa cells) (Fig. 10). Additionally, Ebrahimi et al. have developed a PLGA-PEG copolymer system by emulsion method, which encapsulated $\mathrm{Fe}_{3} \mathrm{O}_{4}$ NPs with doxorubicin (DOX) drug. With the controlled DOX release in tumor cells, this
Fig. 10 Schematic representation of the structure of FA-CIS-POLYMER-Fe ${ }_{3} \mathrm{O}_{4}$ nanoparticles and cisplatin loading and release. Reprinted with permission from ref (Yan Zhang 2014) Copyright (2014) Springer Nature

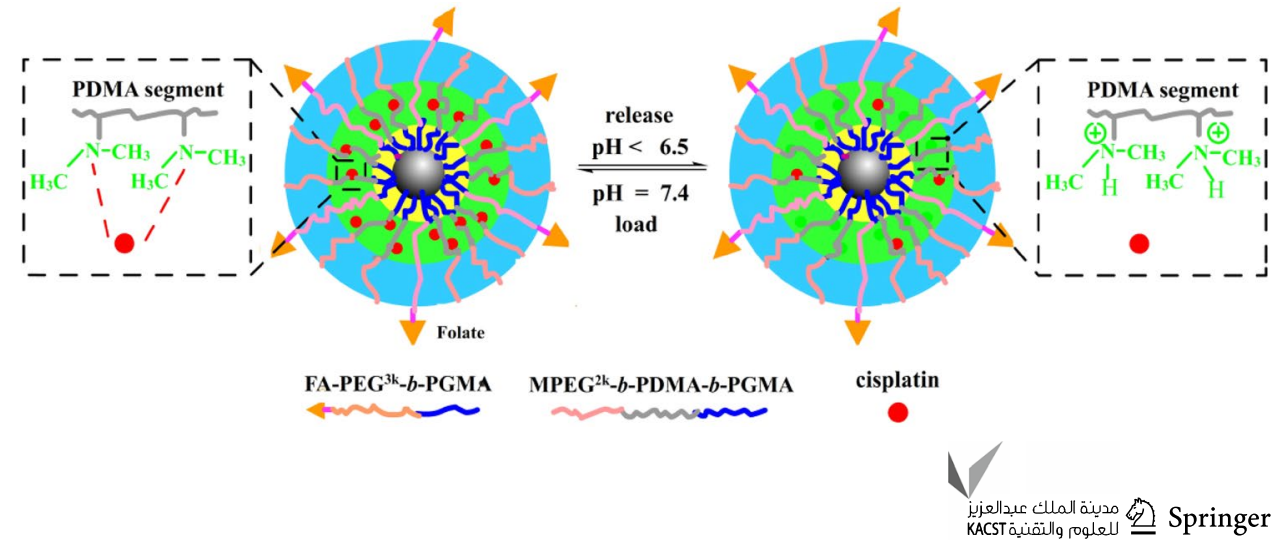


biodegradable nanocomposite was designed to minimize the drug uptake in normal cells and also to control the drug amount and targeting via copolymer coated IONPs and $\mathrm{pH}$. The results revealed that the drug release was high at acidic $\mathrm{pH}$ and found effective as a chemopreventive and chemotherapeutic agent for effective treatment of lung and other solid tumors (Ebrahimi 2014a, b).

Epidermal growth factor receptor (EGFR) is also a wellknown targeting moiety, which has been well-explored for the targeted drug delivery in cancer cells. Utilizing this strategy, Xupeng et al. have developed a multifunctional nanocomposite consisting of IONPs and shown applications in the diagnosis, targeting, and chemo and photothermal therapy of cancer (Xupeng Mu 2017). The nanocomposite was designed by conjugating EGFR antibody on polydopaminecoated $\mathrm{Fe}_{3} \mathrm{O}_{4}$ NPs and loaded with DOX. This nanocomposite exhibited $\mathrm{pH}$ and NIR triggered drug release, which resulted in effective inhibition of colon cancer cells (DLD1, exhibiting overexpression of EGFR) due to synergistic chemo and photothermal therapy. Additionally, these nanocomposites were also utilized for $\mathrm{T}_{2}$ contrast generation to follow the tumor growth by MRI scanning under in vivo experimental condition. In another attempt, Arachchige et al., synthesized dextran coated IONPs and conjugated them with DOX and fluorescein isothiocyanate (Fig. 11). The so produced IONPs laid an efficient combination platform for imaging through $\mathrm{Fe}_{3} \mathrm{O}_{4}$ contrast (MRI), red fluorescence (auto fluorescing DOX) and green fluorescence (fluorescein isothiocyanate). Results revealed that significant drug internalization was obtained in pancreatic cancer cells (MIA PaCa-2 cells). Further, the dual-fluorescent tracking mode showed that the DOX was cleaved from the NPs and accumulated at the targeting site (nucleus). Such strategies could also be utilized for conjugation of an additional antibody to the existing NPs platform, which could be helpful in a tumor specific therapy (Arachchige et al. 2017).

Jia et al. constructed a nanocarrier with PLGA polymer encapsulating IONPs and DOX. The drug internalization study was performed in multiple cancer cell culture models such as Lewis lung carcinoma (LLC), human osteosarcoma (OS-732), and murine-leukemic monocyte-macrophage (RAW 264.7) cell lines and results revealed that IONPsDOX combination was internalized in cells in higher amount with respect to when DOX alone was used. In addition, a higher concentration of IONPs-DOX internalization induced apoptosis in LLC cell line. Under In vivo experiments, results showed that more anti-tumor effect was seen with combination therapy, which was further improved in presence of external magnet (Jia et al. 2012).

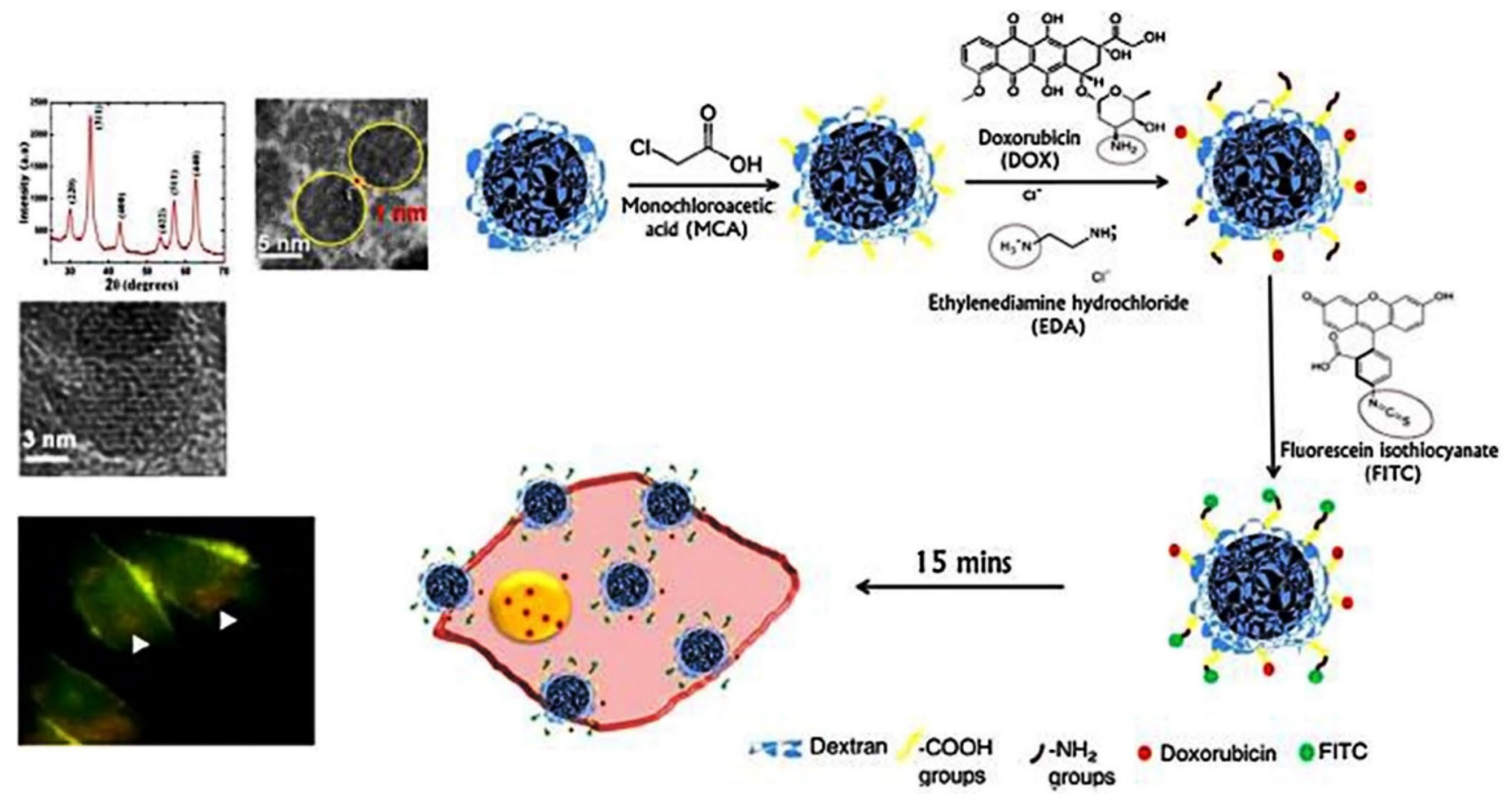

Fig. 11 Synthesis and functionalization of superparamagnetic iron oxide (SPIO) nanoparticles for rapid cellular entry and release of the cancer drug Doxorubicin (DOX) in human pancreatic cancer cells. Dextran coated $\mathrm{Fe}_{3} \mathrm{O}_{4}$ core with DOX (red fluorescence) and FITC (green fluorescence) surface conjugation chemistry, and the rapid entry $(15 \mathrm{~min})$ and intracellular release and accumulation of the cancer drug in the nucleus (white arrow head) of human pancreatic cancer Mia Paca-2 cells.. Reprinted with permission from ref (Arachchige et al. 2017) Copyright (2017) Elsevier 
The blood-brain barrier is a semipermeable membrane that protects neural tissue from toxins and exogenous substances. The tight junctions in the endothelial cells around the capillaries are responsible for the barrier formation. Daunorubicin (DNR) is a potent topoisomerase inhibitor and used as an effective chemotherapeutic agent to treat leukemia and neuroblastoma. Xuhua et al. synthesized DNR loaded $\mathrm{Fe}_{3} \mathrm{O}_{4} \mathrm{NPs}$ and found the formulation was efficient enough to cross the blood-brain barrier which separates the circulating blood from the brain. Results suggested that the combination therapy can trigger apoptosis in glioma cells and thus used as a promising agent to cross the otherwise impermeable blood-brain barrier and treat brain tumors (Xuhua Mao 2016). Experimental data indicated that the formulation increased the barrier permeability through opening tight junctions via controlling the expression of cell-cell adhesion proteins (E-cadherin, ZO-1, and Claudin-1). Homoharringtonine (HTT) conjugated $\mathrm{Fe}_{3} \mathrm{O}_{4}$ NPs were synthesized by Chen et al. to inhibit leukemia. Results showed NPs and drug combination enhanced the inhibitory effect on myeloid leukemia cell lines compared to HTT exposure alone. They found cell death was caused due to apoptosis and observed cell cycle arrest at G0/G1 phase. Moreover, in vivo studies explained the combination worked efficiently to decrease the tumor volume compared to drug alone (Chen et al. 2016). A similar study explained the combination of $\mathrm{Fe}_{3} \mathrm{O}_{4}$ with adriamycin or daunorubicin drugs showed a potential inhibitory effect on lymphoma. A detailed study on Raji cells explained that the inhibition was due to induction of apoptosis which was further enhanced in the presence of NPs (Hongmei Jing 2010). Huilan et al. designed a nanocomposite encompassing $\mathrm{Fe}_{3} \mathrm{O}_{4}$ NPs and an anticancer drug ursolic methyl ester. They demonstrated combination treatment increased the rate of apoptosis in drug-resistant human leukemia cells (KA cells) compared to the drug alone. The authors suggested that this approach to inhibit the growth of drug-resistant cancer cells can be used as an alternative method to treat other cancers as well (Huilan Yue 2016).

Osteoporosis is a condition where bones become weak and brittle due to an imbalance between osteoblasts and osteoclasts (OCs). Thus, reducing the OCs activity, which involves the breakdown of bone tissues, can improve the bone damage. To overcome the effect a composite nanosystem was developed using $\mathrm{Fe}_{3} \mathrm{O}_{4}$ NPs with alendronate drug for treating osteoporosis. In this novel strategy, after the delivery of NPs near osteoclasts (OCs) cells, a dose of radiofrequency was applied to induce thermolysis to OCs. It was also suggested that these multifunctional NPs with their drug delivery, thermolysis, and contrast (MRI) generation ability can be used as a potential therapeutic and imaging agent for osteoporosis (Lee et al. 2016).

\section{Gene delivery applications}

Gene delivery is a therapeutic technique for the delivery of nucleic acids instead of drugs or surgery to treat diseases. In general, it is a great challenge to deliver biological drugs like siRNA, and plasmid DNA to target cells or tissues without being damaged by nucleases. Therefore, to overwhelm the damage, nanocarriers like IONPs have been used to transport the genes and release at the intended target sites (Kievit and Zhang 2011). Borroni et al. developed a novel vector that can deliver therapeutic genes for treating tumors. The genecarrier contained IONPs conjugated with lentiviral vectors to deliver target gene at the area of interest (Fig. 12). To check the efficiency, this nanocarrier was injected with a reporter GFP gene (green fluorescent protein) into a tumor bearing mice and found sustained gene expression near the target areas. Their data suggest that in future LV-MNPs can be successfully tailored to deliver therapeutic genes for selectively inhibiting the growth of tumors (Borroni et al. 2017). Additionally, Mahajan et al. designed a novel IONPs carrier to stop the progression of pancreatic cancer. IONPs were coupled with siRNA (siPLK1) directed against Pololike kinase-1 (cell cycle-specific serine-threonine-kinase). Moreover, siPLK1-IONPs were conjugated to membrane translocation peptide (myristoylated polyarginine peptides (MPAP)) for driving endosomal escape and mediating transport to the cytoplasm and a tumor-selective peptide underglycosylated MUC1 (uMUC1)-specific peptide (EPPT1) to increase intracellular and tumor-specific delivery. The
Fig. 12 Magnetic nanoparticles (MNPs) coupled with lentiviral vectors (LVs) as multifunctional and efficient tools to selectively induce transgene expression in solid tumor for therapeutic purposes. Reprinted with permission from ref (Borroni et al. 2017) Copyright (2017) Elsevier
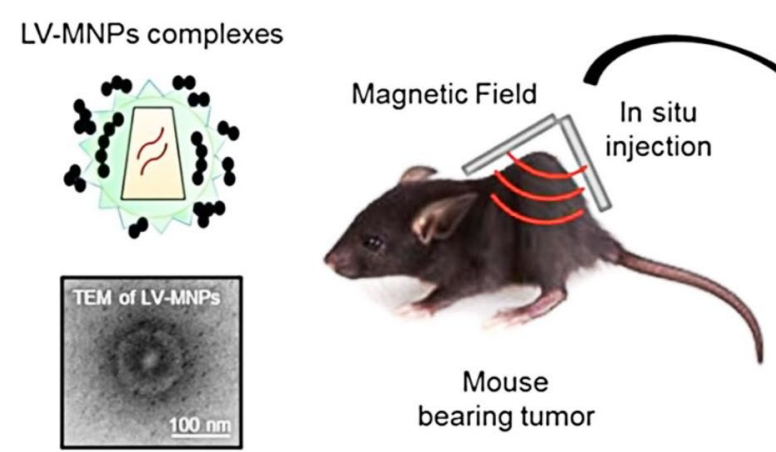

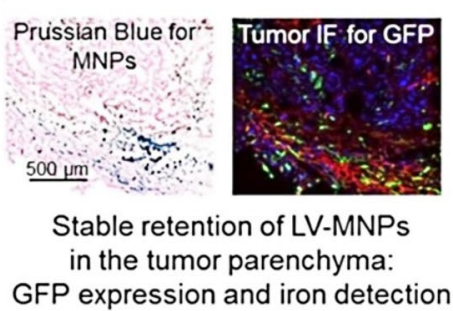

GFP expression and iron detection

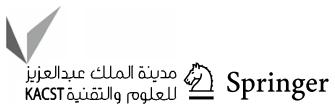


experimental data revealed the significant accumulation of NPs and resulted in efficient PLK1 silencing that leads to tumor suppression through increased apoptosis (Mahajan et al. 2016).

Cheong et al. synthesized IONPs-based carrier loaded with water-soluble chitosan and linoleic acid (SCLNs) for targeting hepatocytes. Authors confirmed the NPs localization in the liver cells by injecting a nuclear isomer (Technetium-99m) labeled SCLNs in mice using nuclear and magnetic resonance imaging. Further SCLN/enhanced GFP (pEGFP) complexes transfected in primary hepatocytes, intravenous administration in mice showed a significant increase in GFP expression. In addition, the gene silencing was effectively achieved by injecting SCLN complexes containing specific siRNA into mice. Thus, the results suggested that SCLNs can be used as a useful platform for imaging and gene delivery simultaneously (Cheong et al. 2009).

In addition, Ling-Feng et al. evaluated the use of IONPs as ideal gene-carrier for PTEN (Phosphatase and tensin homolog) gene delivery to reverse cisplatin-resistance in lung cancer. PTEN acts as a tumor suppressor gene and its inactivity causes the development of several cancers. A549/ CDDP (cisplatin-resistant) cells were transfected with wild PTEN gene expression plasmid (pGFP-PTEN) using IONPs and liposomes as carriers. It was observed The IONPs mediated PTEN transfection showed higher efficiency and more PTEN expression compared to empty liposome-mediated transfection. Further, PTEN transfection increased the apoptotic cell population and enhanced the sensitivity of A549/ CDDP cells to cisplatin indicating PTEN can be an effective target against cisplatin-resistant lung cancer cells (Ling-feng Min 2012) (Table 4).

\section{Iron oxide nanoparticles as broad spectrum antimicrobial agent}

Although IONPs have shown tremendous applications in drug delivery, phototherapy, and chemotherapy, they have also found overarching potential as the antimicrobial and antifungal agent. In the context of drug resistance in microbes, the developments of new drugs or novel strategies for efficient destruction of these pathogens need immediate attention. It is well known that antimicrobial resistance poses a catastrophic threat to humans because if it continues to grow with the current pace for 20 more years, it is estimated that people visiting hospitals for even minor surgery may die due to an ordinary microbial infection, which cannot be treated by antibiotics. It is estimated that the number of deaths due to microbial infection would surpass the mortality due to cancer or diabetes in few decades. Therefore, novel antimicrobials are needed to avoid these circumstances in near future. Nanomaterials offer several advantages over traditional antibiotics as effective antimicrobials, as microbes may not be able to develop resistance against these inorganic materials, therefore, it is expected that the antimicrobial activity of nanomaterials would remain same, even after multiple uses, which is one of the biggest limitations with antibiotics. Among nanomaterials, IONPs are well explored as an effective antimicrobial candidate. Studies on IONPs showed potential antimicrobial activity and literature studies revealed citrate coated $\mathrm{Fe}_{3} \mathrm{O}_{4}$ NPs have an inhibitory effect on Escherichia coli, Bacillus subtilis, Candida albicans, Aspergillus niger and Fusarium solani (Arakha et al. 2015; Nehra et al. 2018). Further, Patra et al. applied green synthesis for the synthesis of $\mathrm{Fe}_{3} \mathrm{O}_{4} \mathrm{NPs}$ from corn plant extract and explained that NPs exerted a synergistic antibacterial and anticandidal activity (Patra et al. 2017). In another attempt, a green chemistry approach using Couroupita guianensis fruit extract was applied to synthesize $\mathrm{Fe}_{3} \mathrm{O}_{4}$ NPs and the particles exhibited potent bactericidal action on several human pathogens (Gao et al. 2017). Additionally, Ismail et al. synthesized IONPs $\left(\alpha-\mathrm{Fe}_{2} \mathrm{O}_{3}\right)$ and determined their antibacterial activity against Gram-positive and Gram-negative bacteria and stated that IONPs can capture Staphylococcus aureus through magnetic field effect (Ismail et al. 2015). Arokiyaraj et al. have developed IONPs treated with Argemone mexicana L. leaf extract and showed a significant colony growth inhibition against Escherichia coli and Proteus mirabilis (Arokiyaraj 2013). As discussed above, more strategies could be devised to develop synergistic IONPs platform, which can be used as a carrier system to treat microbial diseases in future.

\section{Summary and future perspectives}

IONPs with their magnetic characteristics and contrast have already successfully applied in areas of biomedicine, including diagnostics as a probe (MRI scanning) for detection of diseases or disorders in the brain, cardiovascular, liver, blood vessels and other vital organs. Moreover, with advancements, IONPs are prepared in combinations to achieve multiple functions in a single stage like $T_{1}$ and $\mathrm{T}_{2}$ MRI, and PET/CT/NIRF/MRI/PA imaging. Recently IONPs-based nanohybrids were tuned for hyperthermia and PTT, where even low concentrations are capable to enhance the heat generation at the tumor site and can be efficiently used for cellular therapies. In bio-sensing, advances in Nanohybrid IONPs synthesis paved a path to introduce enzyme mimetics, possessing peroxidase, oxidase, and catalase-like activities. In addition, the nanohybrids or conjugated NPs simplified the detection of biomolecules in a single step and laid the foundation to create novel nano-sensors and nano-devices. Further to overcome the obstacles in cancer and multi-drug resistant 
Table 4 Summary of iron oxide NPs applications in drug delivery and gene delivery

\begin{tabular}{|c|c|c|c|}
\hline Nanoparticle/material & Size (nm) & Applications/results & References \\
\hline $\begin{array}{l}\text { IONPs coated with 2-deoxy-D-glucose } \\
\text { and DOX }\end{array}$ & Pore size: 12 & $\begin{array}{l}\text { NPs enhanced chemo-radiotherapy effi- } \\
\text { ciency in breast cancer cells through } \\
\text { targeting. Results showed the com- } \\
\text { bined NPs treatment with doxorubicin } \\
\text { and 2-deoxy-D-glucose boosted the } \\
\text { breast cancer cure through improved } \\
\text { radiotherapy }\end{array}$ & Pirayesh Islamian et al. (2017) \\
\hline $\mathrm{Fe}_{3} \mathrm{O}_{4} \mathrm{NPs}$ & 9 & $\begin{array}{l}\text { Used for treating tumors through cry- } \\
\text { oablation therapy. Results indicated } \\
\text { MCF7 cells were killed efficiently by } \\
\text { cryoablation }\end{array}$ & Ye et al. (2017) \\
\hline $\begin{array}{l}\mathrm{Fe}_{3} \mathrm{O}_{4} \text { NPs @ PEG, folate and cisplatin } \\
\text { (Folic acid-Polymer conjugated } \mathrm{Fe}_{3} \mathrm{O}_{4} \\
\mathrm{NP}_{\mathrm{s}} \text { with cisplatin) }\end{array}$ & $\sim 10$ & $\begin{array}{l}\text { Used for ligand-mediated targeting } \\
\text { and chemotherapy. Cisplatin-loaded } \\
\text { NPs showed concentration dependent } \\
\text { cytotoxicity in HeLa cells. Moreover } \\
\text { folate conjugation exhibited more } \\
\text { cytotoxicity compared to non-conju- } \\
\text { gated NPs }\end{array}$ & Yan Zhang (2014) \\
\hline DOX encapsulated $\mathrm{Fe}_{3} \mathrm{O}_{4}$ & $\sim 12$ & $\begin{array}{l}\text { Used as a nano-carrier for anticancer } \\
\text { drugs like doxorubicin. NPs can be } \\
\text { applied as a chemotherapeutic system } \\
\text { for treating lung cancers }\end{array}$ & Ebrahimi et al. $(2014 a, b)$ \\
\hline $\begin{array}{l}\text { Polydopamine coated } \mathrm{Fe}_{3} \mathrm{O}_{4} \text { with EGFR } \\
\text { antibody and DOX }\end{array}$ & $\sim 60$ & $\begin{array}{l}\text { Used as a multifunctional composites in } \\
\text { diagnosis (MRI imaging) and cancer } \\
\text { treatment (chemo-photo thermal } \\
\text { therapy). Results showed the combi- } \\
\text { nation therapy is efficient enough in } \\
\text { killing EGFR expressed tumor cells } \\
\text { (colon cancer) }\end{array}$ & Xupeng Mu (2017) \\
\hline $\begin{array}{l}\text { Dextran coated IONPs with FITC and } \\
\text { DOX }\end{array}$ & $\sim 8$ & $\begin{array}{l}\text { Used for drug delivery with multimodal } \\
\text { imaging (MRI and FITC Fluores- } \\
\text { cence) and cancer treatment (drug and } \\
\text { hyperthermia) } \\
\text { Can be applied for treating pancreatic } \\
\text { cancers }\end{array}$ & Arachchige et al. (2017) \\
\hline $\begin{array}{l}\text { MNPs encapsulated in PLGA with } \\
\text { DOX }\end{array}$ & $\begin{array}{l}\text { MNPs: } 4-6 \\
\text { DOX-MNPs: } 200-300\end{array}$ & $\begin{array}{l}\text { Used as a nano-carrier for drugs like } \\
\text { doxorubicin. Results showed DOX- } \\
\text { MNPs were internalized in to lung } \\
\text { cancer cells (Lewis lung carcinoma } \\
\text { cells) and induced apoptosis. Moreo- } \\
\text { ver in vivo studies revealed more } \\
\text { anti-tumor activity in presence of an } \\
\text { external magnetic field }\end{array}$ & Jia et al. (2012) \\
\hline $\begin{array}{l}\text { DOX loaded } \mathrm{Fe}_{3} \mathrm{O}_{4} \text {-reduced graphene } \\
\text { oxide }\end{array}$ & $8-10$ & $\begin{array}{l}\text { Showed maximum inhibition of HeLa } \\
\text { cells with hyperthermia assisted } \\
\text { treatment }\end{array}$ & Gupta (2018) \\
\hline Daunorubicin loaded $\mathrm{Fe}_{3} \mathrm{O}_{4} \mathrm{NPs}$ & 100 & $\begin{array}{l}\text { Used to treat brain glioma. Results } \\
\text { showed this drug loaded NPs can be } \\
\text { efficiently delivered into blood brain } \\
\text { barrier and can act as promising drug } \\
\text { to treat blood tumors }\end{array}$ & Xuhua Mao (2016) \\
\hline $\begin{array}{l}\text { Homoharringtonine conjugated } \mathrm{Fe}_{3} \mathrm{O}_{4} \\
\text { NPs }\end{array}$ & 11.2 & $\begin{array}{l}\text { Used for in vitro and in vivo chemo- } \\
\text { therapy towards hematological } \\
\text { malignancy. Results indicated drug } \\
\text { conjugated MNPs injected in tumor } \\
\text { bearing mice (leukemia) showed a } \\
\text { significant decrease in tumor growth } \\
\text { compared to drug treatment alone }\end{array}$ & Chen et al. (2016) \\
\hline
\end{tabular}
compared to drug treatment alone 
Table 4 (continued)

\begin{tabular}{|c|c|c|c|}
\hline Nanoparticle/material & Size (nm) & Applications/results & References \\
\hline Liposome with paclitaxel and SPIONs & $159-168$ & $\begin{array}{l}\text { Comprising both MRI and antitumor } \\
\text { characteristics. Results showed } \\
\text { the tumor growth was supressed in } \\
\text { MDA-MB-231 tumor-bearing mice } \\
\text { compared to controls }\end{array}$ & Zheng et al. (2018) \\
\hline $\begin{array}{l}\mathrm{Fe}_{3} \mathrm{O}_{4} \text { NPs with adriamycin and dau- } \\
\text { norubicin }\end{array}$ & - & $\begin{array}{l}\text { Used as a combination therapy to treat } \\
\text { lymphoma. Results revealed increased } \\
\text { apoptosis in Raji cells and upregu- } \\
\text { lation of p53, down regulation of } \\
\text { NF-kB was observed with NPs drug } \\
\text { combination treatment }\end{array}$ & Hongmei Jing (2010) \\
\hline Cetuximab-IONPs & - & $\begin{array}{l}\text { Both in vitro and in vivo studies } \\
\text { revealed anti-tumor efficiency against } \\
\text { gliomas }\end{array}$ & Freeman et al. (2018) \\
\hline $\mathrm{Fe}_{3} \mathrm{O}_{4}$ NPs with urosilic metyl esters & 10 & $\begin{array}{l}\text { Used as anti-cancer agent for leukae- } \\
\text { mia. NPs and the drug combination } \\
\text { induced apoptosis in drug-resistant } \\
\text { human leukemia KA cells }\end{array}$ & Huilan Yue (2016) \\
\hline $\mathrm{Fe}_{3} \mathrm{O}_{4}$ NPs with alendronate & $\sim 20$ & $\begin{array}{l}\text { Used for treating osteoporosis. Results } \\
\text { showed NPs-drug exposure decreased } \\
\text { the survival rate of osteoclasts com- } \\
\text { pared to control cells and osteoblasts }\end{array}$ & Lee et al. (2016) \\
\hline LV-MNPs & $10-20$ & $\begin{array}{l}\text { Can be applied as a combined therapeu- } \\
\text { tic system to target gene expression in } \\
\text { cancer cells }\end{array}$ & Borroni et al. (2017) \\
\hline IONPs with siRNA & $\begin{array}{l}\text { IONP core: } 9.81 \pm 3.73 \\
\text { Conjugated IONs: } 12.3 \pm 1.4\end{array}$ & $\begin{array}{l}\text { Used for treating pancreatic cancers. } \\
\text { The nano-conjugate with siRNA } \\
\text { resulted in efficient PLK1 silencing } \\
\text { and halted the tumour growth with } \\
\text { increase in apoptosis }\end{array}$ & Mahajan et al. (2016) \\
\hline $\begin{array}{l}\text { IONPs loaded chitosan-linoleic acid } \\
\text { NPs }\end{array}$ & 12 & $\begin{array}{l}\text { Used as a gene delivering system for } \\
\text { targeting hepatocytes and gene silenc- } \\
\text { ing }\end{array}$ & Cheong et al. (2009) \\
\hline IONPs with PTEN gene & - & $\begin{array}{l}\text { Used as gene carriers for PTEN and } \\
\text { applied for reversing cisplatin-resist- } \\
\text { ance in lung cancer }\end{array}$ & Ling-feng Min (2012) \\
\hline
\end{tabular}

diseases, multifunctional IONPs were being designed for diagnosis, targeting, nanocarrier, chemo and phototherapy agents. In conclusion, more progression in the novel synthesis of nanocomposites with multifunctional modalities can find better ways to use IONPs as nano-theranostic entities in biomedicine. The future of IONPs in biomedical applications holds great promise especially in the area of disease diagnosis, early detection, cellular and deep tissue imaging, drug/gene delivery as well as multifunctional therapeutics. Although, Feraheme (US FDA approved) is being used by the consumers, more of such IONPs-based materials need to be researched and made available to the consumer market. The current emphasis of molecular medicine is to develop more novel tools, which can be used for early-stage disease diagnosis and more of point-ofcare diagnostics. Integration of nanomaterials, especially IONPs, could extend the construction of the theranostic platform, which combines therapeutics with diagnostics. Such attempts would primarily make the diagnosis processes simpler, speedier and less invasive. Personalized medicine is also gaining attention and it is expected that the integration of nanotechnology could result in overarching outcomes. In coming years, multifunctional IONPs would be an attractive material for biomedical applications and may change the usual business model of pharmaceutical industries.

Acknowledgements The financial assistance for the Centre for Nanotechnology Research and Applications (CENTRA) by The Gujarat Institute for Chemical Technology (GICT) and the funding from the Department of Science and Technology-Science and Engineering Research Board (SERB) (Grant no.: ILS/SERB/2015-16/01) to Dr Sanjay Singh under the scheme of Start-Up Research Grant (Young Scientists) - Life Sciences are gratefully acknowledged. Dr Singh is also thankful for the financial support provided by the Ahmedabad University as Seed Grant (AU/SG/SAS/DBLS/17-18/03). 


\section{Compliance with ethical standards}

Conflict of interest The authors declare no conflict of interest.

Open Access This article is distributed under the terms of the Creative Commons Attribution 4.0 International License (http://creativeco mmons.org/licenses/by/4.0/), which permits unrestricted use, distribution, and reproduction in any medium, provided you give appropriate credit to the original author(s) and the source, provide a link to the Creative Commons license, and indicate if changes were made.

\section{References}

Aghighi M, Golovko D, Ansari C, Marina NM, Pisani L, Kurlander L, Klenk C, Bhaumik S, Wendland M, Daldrup-Link HE (2015) Imaging tumor necrosis with ferumoxytol. PLoS One 10(11):e0142665. https://doi.org/10.1371/journal.pone.01426 65

Ali A, Atif M, Anees AA, Ansari MQ, Israr MQ, Sadaf JR, Ahmed E, Nur O, Willander M (2013) Potentiometric urea biosensor utilizing nanobiocomposite of chitosan-iron oxide magnetic nanoparticles. J Phys Conf Ser. https://doi.org/10.1088/17426596/414/1/012024

Arachchige MP, Laha SS, Naik AR, Lewis KT, Naik R, Jena BP (2017) Functionalized nanoparticles enable tracking the rapid entry and release of doxorubicin in human pancreatic cancer cells. Micron 92:25-31. https://doi.org/10.1016/j.micron.2016.10.005

Arakha M, Pal S, Samantarrai D, Panigrahi TK, Mallick BC, Pramanik K, Mallick B, Jha S (2015) Antimicrobial activity of iron oxide nanoparticle upon modulation of nanoparticle-bacteria interface. Sci Rep 5:14813. https://doi.org/10.1038/srep14813

Arokiyaraj S, Udaya Prakash MS,NK, Valan Arasu M, Vijayakumar B, Vincent S (2013) Enhanced antibacterial activity of iron oxide magnetic nanoparticles treated with Argemone mexicana L. leaf extract: an in vitro study. Mater Res Bull 48:3323-3327. https://doi.org/10.1016/j.materresbull.2013.05.059

Baby TT, Ramaprabhu S (2011) Non-enzymatic glucose and cholesterol biosensors based on silica coated nano iron oxide dispersed multiwalled carbon nanotubes. Int Conf Nanosci Technol Soc Implications. https://doi.org/10.1109/NSTSI.2011.6111981

Bahrami B, Hojjat-Farsangi M, Mohammadi H, Anvari E, Ghalamfarsa G, Yousefi M, Jadidi-Niaragh F (2017) Nanoparticles and targeted drug delivery in cancer therapy. Immunol Lett 190:64-83. https://doi.org/10.1016/j.imlet.2017.07.015

Bao Y, Sherwood JA, Z S (2018) Magnetic iron oxide nanoparticles as $\mathrm{T} 1$ contrast agents for magnetic resonance imaging. J Mater Chem C 6:1280-1290. https://doi.org/10.1039/C7TC05854C

Barabas K, Milner R, Lurie D, Adin C (2008) Cisplatin: a review of toxicities and therapeutic applications. Vet Comp Oncol 6(1):1-18. https://doi.org/10.1111/j.1476-5829.2007.00142.x

Bashir MR, Bhatti L, Marin D, Nelson RC (2015) Emerging applications for ferumoxytol as a contrast agent in MRI. J Magn Reson Imaging 41(4):884-898. https://doi.org/10.1002/jmri.24691

Bhagat S, Srikanth Vallabani NV, Shutthanandan V, Bowden M, Karakoti AS, Singh S (2017) Gold core/ceria shell-based redox active nanozyme mimicking the biological multienzyme complex phenomenon. J Colloid Interface Sci 513:831-842. https ://doi.org/10.1016/j.jcis.2017.11.064

Boca SC, Potara M, Gabudean AM, Juhem A, Baldeck PL, Astilean $S$ (2011) Chitosan-coated triangular silver nanoparticles as a novel class of biocompatible, highly effective photothermal transducers for in vitro cancer cell therapy. Cancer Lett 311(2):131-140. https://doi.org/10.1016/j.canlet.2011.06.022
Borroni E, Miola M, Ferraris S, Ricci G, Zuzek Rozman K, Kostevsek N, Catizone A, Rimondini L, Prat M, Verne E, Follenzi A (2017) Tumor targeting by lentiviral vectors combined with magnetic nanoparticles in mice. Acta Biomater 59:303-316. https://doi.org/10.1016/j.actbio.2017.07.007

Cai Y, Cao C, He X, Yang C, Tian L, Zhu R, Pan Y (2015) Enhanced magnetic resonance imaging and staining of cancer cells using ferrimagnetic $\mathrm{H}$-ferritin nanoparticles with increasing core size. Int J Nanomed 10:2619-2634. https://doi.org/10.2147/ IJN.S80025

Castaneda RT, Khurana A, Khan R, Daldrup-Link HE (2011) Labeling stem cells with ferumoxytol, an FDA-approved iron oxide nanoparticle. J Vis Exp (57):e3482. https://doi.org/10.3791/3482

Cha R, Li J, Liu Y, Zhang Y, Xie Q, Zhang M (2017) $\mathrm{Fe}_{3} \mathrm{O}_{4}$ nanoparticles modified by CD-containing star polymer for MRI and drug delivery. Colloids Surf B Biointerfaces 158:213-221. https://doi. org/10.1016/j.colsurfb.2017.06.049

Chakravarty R, Valdovinos HF, Chen F, Lewis CM, Ellison PA, Luo H, Meyerand ME, Nickles RJ, Cai W (2014) Intrinsically germanium-69-labeled iron oxide nanoparticles: synthesis and in-vivo dual-modality PET/MR imaging. Adv Mater 26(30):5119-5123. https://doi.org/10.1002/adma.201401372

Chen Z, Yin JJ, Zhou YT, Zhang Y, Song L, Song M, Hu S, Gu N (2012) Dual enzyme-like activities of iron oxide nanoparticles and their implication for diminishing cytotoxicity. ACS Nano 6(5):4001-4012. https://doi.org/10.1021/nn300291r

Chen M, Xiong F, Ma L, Yao H, Wang Q, Wen L, Wang Q, Gu N, Chen $\mathrm{S}$ (2016) Inhibitory effect of magnetic $\mathrm{Fe}_{3} \mathrm{O}_{4}$ nanoparticles coloaded with homoharringtonine on human leukemia cells in vivo and in vitro. Int J Nanomed 11:4413-4422. https://doi. org/10.2147/IJN.S105543

Cheong SJ, Lee CM, Kim SL, Jeong HJ, Kim EM, Park EH, Kim DW, Lim ST, Sohn MH (2009) Superparamagnetic iron oxide nanoparticles-loaded chitosan-linoleic acid nanoparticles as an effective hepatocyte-targeted gene delivery system. Int J Pharm 372(1-2):169-176. https://doi.org/10.1016/j.ijpha rm.2009.01.009

Cormode DP, Naha PC, Fayad ZA (2014) Nanoparticle contrast agents for computed tomography: a focus on micelles. Contrast Media Mol Imaging 9(1):37-52. https://doi.org/10.1002/cmmi.1551

Dasari S, Tchounwou PB (2014) Cisplatin in cancer therapy: molecular mechanisms of action. Eur J Pharmacol 740:364-378. https://doi. org/10.1016/j.ejphar.2014.07.025

de Rosales TM, Tavare R, Paul R, Jauregui-Osoro RL, Protti M, Glaria A, Varma A, Szanda G, Blower I PJ (2011) Synthesis of ${ }^{64} \mathrm{Cu}^{\mathrm{II}_{-}}$ bis(dithiocarbamatebisphosphonate) and its conjugation with superparamagnetic iron oxide nanoparticles: in vivo evaluation as dual-modality PET-MRI agent. Angew Chem Int Ed Engl 50(24):5509-5513. https://doi.org/10.1002/anie.201007894

Ebrahimi E, Akbarzadeh A, Abbasi E, Khandaghi AA, Abasalizadeh F, Davaran S (2014a) Novel drug delivery system based on doxorubicin-encapsulated magnetic nanoparticles modified with PLGA-PEG1000 copolymer. Artif Cells Nanomed Biotechnol. https://doi.org/10.3109/21691401.2014.944646

Ebrahimi E, Khandaghi AA, Valipour F, Babaie S, Asghari F, Motaali S, Abbasi E, Akbarzadeh A, Davaran S (2014b) In vitro study and characterization of doxorubicin-loaded magnetic nanoparticles modified with biodegradable copolymers. Artif Cells Nanomed Biotechnol. https://doi.org/10.3109/21691401.2014.968822

El-Boubbou K (2018) Magnetic iron oxide nanoparticles as drug carriers: clinical relevance. Nanomedicine (Lond). https://doi. org/10.2217/nnm-2017-0336

Elham Cheraghipour SJ, Mehdizadeh AR (2012) Citrate capped superparamagnetic iron oxide nanoparticles used for hyperthermia therapy. J Biomed Sci Eng 5:715-719. https://doi.org/10.4236/ jbise.2012.512089

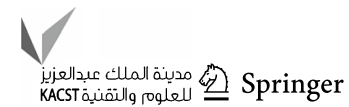


Emily A. Waters SAW (2008) Contrast agents for MRI. Basic Res Cardiol 103(2):114-121. https://doi.org/10.1007/s00395-008-0711-6

Espinosa A, Di Corato R, Kolosnjaj-Tabi J, Flaud P, Pellegrino T, Wilhelm C (2016) Duality of iron oxide nanoparticles in cancer therapy: amplification of heating efficiency by magnetic hyperthermia and photothermal bimodal treatment. ACS Nano 10(2):2436-2446. https://doi.org/10.1021/acsnano.5b07249

Evertsson M, Kjellman P, Cinthio M, Andersson R, Tran TA, In't Zandt R, Grafstrom G, Toftevall H, Fredriksson S, Ingvar C, Strand SE, Jansson T (2017) Combined Magnetomotive ultrasound, PET/ $\mathrm{CT}$, and MR imaging of (68)Ga-labelled superparamagnetic iron oxide nanoparticles in rat sentinel lymph nodes in vivo. Sci Rep 7(1):4824. https://doi.org/10.1038/s41598-017-04396-z

Fayemi OE, Adekunle AS, Ebenso EE (2017) Electrochemical determination of serotonin in urine samples based on metal oxide nanoparticles/MWCNT on modified Glassy Carbon Electrode. Sens Bio Sens Res 13:17-27. https://doi.org/10.1016/j. sbsr.2017.01.005

Fornara A, Johansson P, Petersson K, Gustafsson S, Qin J, Olsson E, Ilver D, Krozer A, Muhammed M, Johansson C (2008) Tailored magnetic nanoparticles for direct and sensitive detection of biomolecules in biological samples. Nano Lett 8(10):3423-3428. https://doi.org/10.1021/n18022498

Freeman AC, Platt SR, Holmes S, Kent M, Robinson K, Howerth E, Eagleson J, Bouras A, Kaluzova M, Hadjipanayis CG (2018) Convection-enhanced delivery of cetuximab conjugated ironoxide nanoparticles for treatment of spontaneous canine intracranial gliomas. J Neurooncol 137(3):653-663. https://doi. org/10.1007/s11060-018-2764-1

Gao L, Fan K, Yan X (2017) Iron oxide nanozyme: a multifunctional enzyme mimetic for biomedical applications. Theranostics 7(13):3207-3227. https://doi.org/10.7150/thno.19738

García RS, Stafford S, YK Gk (2018) recent progress in synthesis and functionalization of multimodal fluorescent-magnetic nanoparticles for biological applications. Appl Sci 8(2):(172):1-23. https ://doi.org/10.3390/app8020172

Gawande MB, Goswami A, Felpin FX, Asefa T, Huang X, Silva R, Zou X, Zboril R, Varma RS (2016) $\mathrm{Cu}$ and $\mathrm{Cu}$-based nanoparticles: synthesis and applications in catalysis. Chem Rev 116(6):37223811. https://doi.org/10.1021/acs.chemrev.5b00482

Gupta AK, Gupta M (2005) Synthesis and surface engineering of iron oxide nanoparticles for biomedical applications. Biomaterials 26(18):3995-4021. https://doi.org/10.1016/j.biomateria ls. 2004.10 .012

Gupta AK, Naregalkar RR, Vaidya VD, Gupta M (2007) Recent advances on surface engineering of magnetic iron oxide nanoparticles and their biomedical applications. Nanomedicine (Lond) 2(1):23-39. https://doi.org/10.2217/17435889.2.1.23

Gupta JPA, Jaiswal M, Agarrwal A, Bahadur D (2018) Superparamagnetic iron oxide-reduced graphene oxide nanohybrid-a vehicle for targeted drug delivery and hyperthermia treatment of cancer. J Magn Magn Mater 448:332-338. https://doi.org/10.1016/j. jmmm.2017.05.084

He R, Wang YC, Wang X, Wang Z, Liu G, Zhou W, Wen L, Li Q, Wang X, Chen X, Zeng J, Hou JG (2014) Facile synthesis of pentacle gold-copper alloy nanocrystals and their plasmonic and catalytic properties. Nat Commun 5:4327. https://doi.org/10.1038/ ncomms 5327

Hongmei Jing JW, Ping Yang X, Ke G, Xia B Chen (2010) Magnetic $\mathrm{Fe}_{3} \mathrm{O}_{4}$ nanoparticles and chemotherapy agents interact synergistically to induce apoptosis in lymphoma cells. Int $\mathrm{J}$ Nanomed 5:999-1004. https://doi.org/10.2147/IJN.S14957

Hongwei Chen JB, Zhang F, Zhang J, Paholaka H, Duxin Sun (2014) Highly crystallized iron oxide nanoparticles as effective and biodegradable mediators for photothermal cancer therapy. J Mater Chem B 2(7):757-765
Hope MD, Hope TA, Zhu C, Faraji F, Haraldsson H, Ordovas KG, Saloner D (2015) Vascular imaging with ferumoxytol as a contrast agent. AJR Am J Roentgenol 205(3):W366-373. https://doi. org/10.2214/AJR.15.14534

Huang DM, Hsiao JK, Chen YC, Chien LY, Yao M, Chen YK, Ko BS, Hsu SC, Tai LA, Cheng HY, Wang SW, Yang CS, Chen YC (2009) The promotion of human mesenchymal stem cell proliferation by superparamagnetic iron oxide nanoparticles. Biomaterials 30(22):3645-3651. https://doi.org/10.1016/j.biomateria 1s.2009.03.032

Huber DL (2005) Synthesis, properties, and applications of iron nanoparticles. Small 1(5):482-501. https://doi.org/10.1002/ smll.200500006

Huilan Yue GZ, Xiaohang Liu C, Li T, Zhou Y, Tao Y, Kang J, Tang SY, Liu B, Xin Zeng,Gen Zhang (2016) $\mathrm{Fe}_{3} \mathrm{O}_{4}$ nanoparticles with Ursolic methyl ester induce apoptosis of multidrug-resistant leukemia KA cell: in vitro evaluation. J Nanosci Nanotechnol (16):7140-7144. https://doi.org/10.1166/jnn.2016.11365

Isa Karimzadeh MA, Taher Doroudi MR, Ganjali, Peir Hossein Kolivand (2017) Superparamagnetic iron Oxide $\left(\mathrm{Fe}_{3} \mathrm{O}_{4}\right)$ nanoparticles coated with PEG/PEI for biomedical applications: a facile and scalable preparation route based on the cathodic electrochemical deposition method. Adv Phys Chem 2017:1-7. https:// doi.org/10.1155/2017/9437487

Ismail RA, Sulaiman GM, Abdulrahman SA, Marzoog TR (2015) Antibacterial activity of magnetic iron oxide nanoparticles synthesized by laser ablation in liquid. Mater Sci Eng C Mater Biol Appl 53:286-297. https://doi.org/10.1016/j.msec.2015.04.047

Jha GSVLSS., C PK,MJ R, N S, S S (2017) Green synthesis of magnetic $\mathrm{Fe} 3 \mathrm{O} 4$ nanoparticles using Couroupita guianensis Aubl. fruit extract for their antibacterial and cytotoxicity activities. Artif Cells Nanomed Biotechnol:1-10. https://doi. org/10.1080/21691401.2017.1332635

Jia Y, Yuan M, Yuan H, Huang X, Sui X, Cui X, Tang F, Peng J, Chen J, Lu S, Xu W, Zhang L, Guo Q (2012) Co-encapsulation of magnetic $\mathrm{Fe}_{3} \mathrm{O}_{4}$ nanoparticles and doxorubicin into biodegradable PLGA nanocarriers for intratumoral drug delivery. Int $\mathrm{J}$ Nanomedicine 7:1697-1708. https://doi.org/10.2147/IJN.S28629

Ju Y, Zhang H, Yu J, Tong S, Tian N, Wang Z, Wang X, Su X, Chu X, Lin J, Ding Y, Li G, Sheng F, Hou Y (2017) Monodisperse $\mathrm{Au}-\mathrm{Fe}_{2} \mathrm{C}$ Janus nanoparticles: an attractive multifunctional material for triple-modal imaging-guided tumor photothermal therapy. ACS Nano 11(9):9239-9248. https://doi.org/10.1021/ acsnano.7b04461

Kacar C, Erden PE, Pekyardimci S, Kilic E (2013) An $\mathrm{Fe}_{3} \mathrm{O}_{4}$-nanoparticles-based amperometric biosensor for creatine determination. Artif Cells Nanomed Biotechnol 41(1):2-7. https ://doi.org/10.3109/10731199.2012.712044

Kandasamy GSA, Bhati P, Chakrabarty A, Maity D (2018a) Systematic investigations on heating effects of carboxyl-amine functionalized superparamagnetic iron oxide nanoparticles (SPIONs) based ferrofluids for in vitro cancer hyperthermia therapy. J Mol Liq 256:224-237. https://doi.org/10.1016/j.molliq.2018.02.029

Kandasamy GSA, Luthra T, Saini K, Maity D (2018b) Functionalized hydrophilic superparamagnetic iron oxide nanoparticles for magnetic fluid hyperthermia application in liver cancer treatment. ACS Omega 3(4):3991-4005. https://doi.org/10.1021/acsom ega. 8 b00207

Karim MN, Anderson SR, Singh S, Ramanathan R, Bansal V (2018) Nanostructured silver fabric as a free-standing NanoZyme for colorimetric detection of glucose in urine. Biosens Bioelectron 110:8-15. https://doi.org/10.1016/j.bios.2018.03.025

Kievit FM, Zhang M (2011) Surface engineering of iron oxide nanoparticles for targeted cancer therapy. Acc Chem Res 44(10):853862. https://doi.org/10.1021/ar2000277 
Kolosnjaj-Tabi J, Wilhelm C (2017) Magnetic nanoparticles in cancer therapy: how can thermal approaches help? Nanomedicine (Lond) 12(6):573-575. https://doi.org/10.2217/nnm-2017-0014

Larson TA, Joshi PP, Sokolov K (2012) Preventing protein adsorption and macrophage uptake of gold nanoparticles via a hydrophobic shield. ACS Nano 6(10):9182-9190. https://doi.org/10.1021/ nn3035155

Lee HY, Li Z, Chen K, Hsu AR, Xu C, Xie J, Sun S, Chen X (2008) PET/MRI dual-modality tumor imaging using arginine-glycineaspartic (RGD)-conjugated radiolabeled iron oxide nanoparticles. J Nucl Med 49(8):1371-1379. https://doi.org/10.2967/ jnumed.108.051243

Lee MS, Su CM, Yeh JC, Wu PR, Tsai TY, Lou SL (2016) Synthesis of composite magnetic nanoparticles $\mathrm{Fe}_{3} \mathrm{O}_{4}$ with alendronate for osteoporosis treatment. Int J Nanomed 11:4583-4594. https://doi. org/10.2147/IJN.S112415

Liang H, Liu B, Yuan Q, Liu J (2016) Magnetic iron oxide nanoparticle seeded growth of nucleotide coordinated polymers. ACS Appl Mater Interfaces 8(24):15615-15622. https://doi.org/10.1021/ acsami.6b04038

Lin T, Zhong L, Guo L, Fu F, Chen G (2014a) Seeing diabetes: visual detection of glucose based on the intrinsic peroxidase-like activity of $\mathrm{MoS}_{2}$ nanosheets. Nanoscale 6(20):11856-11862. https:// doi.org/10.1039/c4nr03393k

Lin T, Zhong L, Song Z, Guo L, Wu H, Guo Q, Chen Y, Fu F, Chen G (2014b) Visual detection of blood glucose based on peroxidaselike activity of $\mathrm{WS}_{2}$ nanosheets. Biosens Bioelectron 62:302307. https://doi.org/10.1016/j.bios.2014.07.001

Lin Y, Huang Y, Ren J, Qu X (2014c) Incorporating ATP into biomimetic catalysts for realizing exceptional enzymatic performance over a broad temperature range. Npg Asia Mater 6:e114. https:// doi.org/10.1038/am.2014.42

Lin Y, Ren J, Qu X (2014d) Catalytically active nanomaterials: a promising candidate for artificial enzymes. Acc Chem Res 47(4):1097-1105. https://doi.org/10.1021/ar400250z

Lindholm P, Minn H, Leskinen-Kallio S, Bergman J, Ruotsalainen U, Joensuu H (1993) Influence of the blood glucose concentration on FDG uptake in cancer-a PET study. J Nucl Med 34(1):1-6

Ling-feng Min L-1H, Chen Q, Yu Q, Ming-xuan X (2012) Magnetic iron oxide nanoparticles carrying PTEN gene to reverse cisplatin-resistance of A549/CDDP cell lines. J Central South Univ 19:331-339. https://doi.org/10.1007/s11771-012-1009-2

Liu Z, Cai W, He L, Nakayama N, Chen K, Sun X, Chen X, Dai H (2007) In vivo biodistribution and highly efficient tumour targeting of carbon nanotubes in mice. Nat Nanotechnol 2(1):47-52. https://doi.org/10.1038/nnano.2006.170

Liu J, Xu J, Zhou J, Zhang Y, Guo D, Wang Z (2017) $\mathrm{Fe}_{3} \mathrm{O}_{4}$-based PLGA nanoparticles as MR contrast agents for the detection of thrombosis. Int J Nanomedicine 12:1113-1126. https://doi. org/10.2147/IJN.S123228

Mahajan UM, Teller S, Sendler M, Palankar R, van den Brandt C, Schwaiger T, Kuhn JP, Ribback S, Glockl G, Evert M, Weitschies W, Hosten N, Dombrowski F, Delcea M, Weiss FU, Lerch MM, Mayerle J (2016) Tumour-specific delivery of siRNA-coupled superparamagnetic iron oxide nanoparticles, targeted against PLK1, stops progression of pancreatic cancer. Gut 65(11):18381849. https://doi.org/10.1136/gutjnl-2016-311393

Mahato K, Kumar A, Maurya PK, Chandra P (2018a) Shifting paradigm of cancer diagnoses in clinically relevant samples based on miniaturized electrochemical nanobiosensors and microfluidic devices. Biosens Bioelectron 100:411-428. https://doi. org/10.1016/j.bios.2017.09.003

Mahato K, Maurya PK, Chandra P (2018b) Fundamentals and commercial aspects of nanobiosensors in point-of-care clinical diagnostics. 3 Biotech 8(3):149. https://doi.org/10.1007/s1320 5-018-1148-8
Mazario E, Belkahla AF,H, Lomas JS, Decorse P, Chevillot-Biraud A, Verbeke P, Wilhelm C, Ammar S, El Hage J-M, Chahine M, Hemadi (2017) Functionalization of iron oxide nanoparticles with HSA protein for thermal therapy. IEEE Trans Magn 53 (11). https://doi.org/10.1109/TMAG.2017.2707599

Monaco I, Arena F, Biffi S, Locatelli E, Bortot B, La Cava F, Marini GM, Severini GM, Terreno E, Comes Franchini M (2017) Synthesis of lipophilic core-shell $\mathrm{Fe}_{3} \mathrm{O}_{4} @ \mathrm{SiO}_{2} @ \mathrm{Au}$ nanoparticles and polymeric entrapment into nanomicelles: a novel nanosystem for in vivo active targeting and magnetic resonance-photoacoustic dual imaging. Bioconjug Chem 28(5):1382-1390. https://doi. org/10.1021/acs.bioconjchem.7b00076

Mónica Carril IF, Juan Rodríguez I, Penadés GS (2014) Gold-coated iron oxide glyconanoparticles for MRI, CT, and US multimodal imaging. Part Part Syst Charact 31:81-87. https://doi. org/10.1002/ppsc.201300239

Naha PC, Zaki AA, Hecht E, Chorny M, Chhour P, Blankemeyer E, Yates DM, Witschey WR, Litt HI, Tsourkas A, Cormode DP (2014) Dextran coated bismuth-iron oxide nanohybrid contrast agents for computed tomography and magnetic resonance imaging. J Mater Chem B 2(46):8239-8248. https://doi.org/10.1039/ C4TB01159G

Nahrendorf M, Zhang H, Hembrador S, Panizzi P, Sosnovik DE, Aikawa E, Libby P, Swirski FK, Weissleder R (2008) Nanoparticle PET-CT imaging of macrophages in inflammatory atherosclerosis. Circulation 117(3):379-387. https://doi.org/10.1161/ CIRCULATIONAHA.107.741181

Navvabeh Salarizadeh MS, Farhood Heydari, Seyyed Salman Seyyed Afghahi (2017) Preparation and physico-biochemical characterization of $(\mathrm{Fe}, \mathrm{Co}, \mathrm{Ni})$ oxide nanoparticles-decorated PANIMWCNTs as peroxidase mimetics. New J Chem 41:1404914052. https://doi.org/10.1039/C7NJ02645E

Nehra P, Chauhan RP, Garg N, Verma K (2018) Antibacterial and antifungal activity of chitosan coated iron oxide nanoparticles. Br J Biomed Sci 75(1):13-18. https://doi.org/10.1080/09674 845.2017.1347362

Niu C, Xu Y, An S, Zhang M, Hu Y, Wang L, Peng Q (2017) Nearinfrared induced phase-shifted ICG/ $/ \mathrm{Fe}_{3} \mathrm{O}_{4}$ loaded PLGA nanoparticles for photothermal tumor ablation. Sci Rep 7(1):5490. https://doi.org/10.1038/s41598-017-06122-1

Nor NMRK., Lockman Z (2017) Physical and electrochemical properties of iron oxide nanoparticles-modified electrode for amperometric glucose detection. Electrochim Acta 248:160-168. https ://doi.org/10.1016/j.electacta.2017.07.097

Patra JK, Ali MS, Oh IG, Baek KH (2017) Proteasome inhibitory, antioxidant, and synergistic antibacterial and anticandidal activity of green biosynthesized magnetic $\mathrm{Fe}_{3} \mathrm{O}_{4}$ nanoparticles using the aqueous extract of corn (Zea mays L.) ear leaves. Artif Cells Nanomed Biotechnol 45(2):349-356. https://doi. org/10.3109/21691401.2016.1153484

Pellico J, Ruiz-Cabello J, Fernandez-Barahona I, Gutierrez L, LechugaVieco AV, Enriquez JA, Morales MP, Herranz F (2017) One-step fast synthesis of nanoparticles for MRI: coating chemistry as the key variable determining positive or negative contrast. Langmuir 33(39):10239-10247. https://doi.org/10.1021/acs.langm uir.7b01759

Perlman O, Azhari H (2017) Ultrasonic computed tomography imaging of iron oxide nanoparticles. Phys Med Biol 62(3):825-842. https ://doi.org/10.1088/1361-6560/aa51ab

Pirayesh Islamian J, Hatamian M, Aval NA, Rashidi MR, Mesbahi A, Mohammadzadeh M, Asghari Jafarabadi M (2017) Targeted superparamagnetic nanoparticles coated with 2-deoxy-D-glucose and doxorubicin more sensitize breast cancer cells to ionizing radiation. Breast 33:97-103. https://doi.org/10.1016/j.breas t.2017.03.009

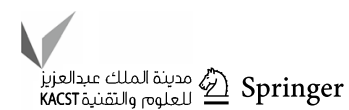


Pu F, Ren J, Qu X (2017) Nucleobases, nucleosides, and nucleotides: versatile biomolecules for generating functional nanomaterials. Chem Soc Rev 47:1285-1306. https://doi.org/10.1039/c7cs0 0673j

Reguera J, Jimenez de Aberasturi D, Henriksen-Lacey M, Langer J, Espinosa A, Szczupak B, Wilhelm C, Liz-Marzan LM (2017) Janus plasmonic-magnetic gold-iron oxide nanoparticles as contrast agents for multimodal imaging. Nanoscale 9(27):94679480. https://doi.org/10.1039/c7nr01406f

Ren Y, Zhang H, Chen B, Cheng J, Cai X, Liu R, Xia G, Wu W, Wang S, Ding J, Gao C, Wang J, Bao W, Wang L, Tian L, Song H, Wang X (2012) Multifunctional magnetic $\mathrm{Fe}_{3} \mathrm{O}_{4}$ nanoparticles combined with chemotherapy and hyperthermia to overcome multidrug resistance. Int J Nanomed 7:2261-2269. https://doi. org/10.2147/IJN.S29357

Shah J, Singh S (2018) Unveiling the role of ATP in amplification of intrinsic peroxidase-like activity of gold nanoparticles. 3 Biotech 8(1):67. https://doi.org/10.1007/s13205-017-1082-1

Shah J, Purohit R, Singh R, Karakoti AS, Singh S (2015) ATPenhanced peroxidase-like activity of gold nanoparticles. J Colloid Interface Sci 456:100-107. https://doi.org/10.1016/j. jcis.2015.06.015

Shen S, Kong F, Guo X, Wu L, Shen H, Xie M, Wang X, Jin Y, Ge Y (2013) CMCTS stabilized $\mathrm{Fe}_{3} \mathrm{O}_{4}$ particles with extremely low toxicity as highly efficient near-infrared photothermal agents for in vivo tumor ablation. Nanoscale 5(17):8056-8066. https ://doi.org/10.1039/c3nr01447a

Shen S, Wang S, Zheng R, Zhu X, Jiang X, Fu D, Yang W (2015) Magnetic nanoparticle clusters for photothermal therapy with near-infrared irradiation. Biomaterials 39:67-74. https://doi. org/10.1016/j.biomaterials.2014.10.064

Singh S (2017) Glucose decorated gold nanoclusters: a membrane potential independent fluorescence probe for rapid identification of cancer cells expressing Glut receptors. Colloids Surf B Biointerfaces 155:25-34. https://doi.org/10.1016/j.colsu rfb.2017.03.052

Sohn CH, Park SP, Choi SH, Park SH, Kim S, Xu L, Kim SH, Hur JA, Choi J, Choi TH (2015) MRI molecular imaging using GLUT1 antibody- $\mathrm{Fe}_{3} \mathrm{O}_{4}$ nanoparticles in the hemangioma animal model for differentiating infantile hemangioma from vascular malformation. Nanomedicine 11(1):127-135. https:// doi.org/10.1016/j.nano.2014.08.003

Tan B, Zhao H, Wu W, Liu X, Zhang Y, Quan X (2017) $\mathrm{Fe}_{3} \mathrm{O}_{4}$-AuNPs anchored 2D metal-organic framework nanosheets with DNA regulated switchable peroxidase-like activity. Nanoscale 9(47):18699-18710. https://doi.org/10.1039/c7nr05541b

Thomas R, Park IK, Jeong YY (2013) Magnetic iron oxide nanoparticles for multimodal imaging and therapy of cancer. Int J Mol Sci 14(8):15910-15930. https://doi.org/10.3390/ijms1 40815910

Ulbrich K, Hola K, Subr V, Bakandritsos A, Tucek J, Zboril R (2016) Targeted drug delivery with polymers and magnetic nanoparticles: covalent and noncovalent approaches, release control, and clinical studies. Chem Rev 116(9):5338-5431. https://doi. org/10.1021/acs.chemrev.5b00589

Vallabani NVS, Karakoti AS, Singh S (2017) ATP-mediated intrinsic peroxidase-like activity of $\mathrm{Fe}_{3} \mathrm{O}_{4}$-based nanozyme: One step detection of blood glucose at physiological $\mathrm{pH}$. Colloids Surf B Biointerfaces 153:52-60. https://doi.org/10.1016/j.colsu rfb.2017.02.004

Vasanawala SS, Nguyen KL, Hope MD, Bridges MD, Hope TA, Reeder SB, Bashir MR (2016) Safety and technique of ferumoxytol administration for MRI. Magn Reson Med 75(5):2107-2111. https://doi.org/10.1002/mrm.26151
Vasir JK, Labhasetwar V (2005) Targeted drug delivery in cancer therapy. Technol Cancer Res Treat 4(4):363-374. https://doi. org/10.1177/153303460500400405

Vazquez-Gonzalez M, Torrente-Rodriguez RM, Kozell A, Liao WC, Cecconello A, Campuzano S, Pingarron JM, Willner I (2017) Mimicking peroxidase activities with Prussian Blue nanoparticles and their cyanometalate structural analogues. Nano Lett 17(8):4958-4963. https://doi.org/10.1021/acs.nanolett.7b02102

Wang G, Gao W, Zhang X, Mei X (2016) Au nanocage functionalized with ultra-small $\mathrm{Fe}_{3} \mathrm{O}_{4}$ nanoparticles for targeting T1-T2 dual MRI and CT imaging of tumor. Sci Rep 6:28258. https://doi. org/10.1038/srep28258

Wang S, Cazelles R, Liao WC, Vazquez-Gonzalez M, Zoabi A, AbuReziq R, Willner I (2017) Mimicking horseradish peroxidase and NADH peroxidase by heterogeneous $\mathrm{Cu}(2+)$-modified graphene oxide nanoparticles. Nano Lett 17(3):2043-2048. https:// doi.org/10.1021/acs.nanolett.7b00093

Wang Y, Liu X, Xu X, Yang Y, Huang L, He Z, Xu Y, Chen J, Feng $Z$ (2018) Preparation and characterization of reduced graphene oxide/ $\mathrm{Fe} 3 \mathrm{O} 4$ nanocomposite by a facile in-situ deposition method for glucose biosensor applications. Mater Res Bull 101:340-346. https://doi.org/10.1016/j.materresbull.2018.01.035

Wu Q, Wang X, Liao C, Wei Q, Wang Q (2015a) Microgel coating of magnetic nanoparticles via bienzyme-mediated free-radical polymerization for colorimetric detection of glucose. Nanoscale 7(40):16578-16582. https://doi.org/10.1039/c5nr05716g

Wu W, Wu Z, Yu T, Jiang C, Kim WS (2015b) Recent progress on magnetic iron oxide nanoparticles: synthesis, surface functional strategies and biomedical applications. Sci Technol Adv Mater 16(2):023501. https://doi.org/10.1088/1468-6996/16/2/023501

Xiao N, Gu W, Wang H, Deng Y, Shi X, Ye L (2014) T1-T2 dual-modal MRI of brain gliomas using PEGylated Gd-doped iron oxide nanoparticles. J Colloid Interface Sci 417:159-165. https://doi. org/10.1016/j.jcis.2013.11.020

Xie J, Chen K, Huang J, Lee S, Wang J, Gao J, Li X, Chen X (2010) $\mathrm{PET} / \mathrm{NIRF} / \mathrm{MRI}$ triple functional iron oxide nanoparticles. Biomaterials 31(11):3016-3022. https://doi.org/10.1016/j.bioma terials.2010.01.010

Xuhua Mao ZR, Huang B, Pu M, Li H, Ding Y, Xu Q, Zhang Y, Zhang C, Lu Z, Yuxin Chen, Yanping Zhao (2016) Daunorubicin loaded $\mathrm{Fe}_{3} \mathrm{O}_{4}$ nanoparticles induce apoptosis of glioma cells and disrupt tight junction at blood-brain barrier. J Nanosci Nanotechnol 16:12356-12361. https://doi.org/10.1166/jnn.2016.13762

Xupeng Mu FZ, Kong C, Zhang H, Zhang W, Ge R, Liu Y, Jiang J (2017) EGFR-targeted delivery of DOX-loaded $\mathrm{Fe}_{3} \mathrm{O}_{4} @$ polydopamine multifunctional nanocomposites for MRI and antitumor chemo-photothermal therapy. Int J Nanomed 12:2899-2911. https://doi.org/10.2147/IJN.S131418

Yan Zhang X-jW, Guo M, Hu-sheng Yan (2014) Cisplatin-loaded polymer/magnetite composite nanoparticles as multifunctional therapeutic nanomedicine. Chin J Polym Sci 32:1329 - 1337. https://doi.org/10.1007/s10118-014-1510-1

Yang X, Hong H, Grailer JJ, Rowland IJ, Javadi A, Hurley SA, Xiao Y, Yang Y, Zhang Y, Nickles RJ, Cai W, Steeber DA, Gong S (2011) cRGD-functionalized, DOX-conjugated, and ${ }^{64} \mathrm{Cu}$-labeled superparamagnetic iron oxide nanoparticles for targeted anticancer drug delivery and PET/MR imaging. Biomaterials 32(17):41514160. https://doi.org/10.1016/j.biomaterials.2011.02.006

Yang YC, Wang YT, Tseng WL (2017) Amplified peroxidase-like activity in iron oxide nanoparticles using adenosine monophosphate: application to urinary protein sensing. ACS Appl Mater Interfaces 9(11):10069-10077. https://doi.org/10.1021/acsam i.6b15654

Yavuz MS, Cheng Y, Chen J, Cobley CM, Zhang Q, Rycenga M, Xie J, Kim C, Song KH, Schwartz AG, Wang LV, Xia Y (2009) Gold nanocages covered by smart polymers for controlled release 
with near-infrared light. Nat Mater 8(12):935-939. https://doi. org/10.1038/nmat2564

Ye P, Kong Y, Chen X, Li W, Liu D, Xie Y, Zhou Y, Zou H, Chang Z, Dai H, Kong X, Liu P (2017) $\mathrm{Fe}_{3} \mathrm{O}_{4}$ nanoparticles and cryoablation enhance ice crystal formation to improve the efficiency of killing breast cancer cells. Oncotarget 8(7):11389-11399. https ://doi.org/10.18632/oncotarget.13859

Yu F, Huang Y, Cole AJ, Yang VC (2009) The artificial peroxidase activity of magnetic iron oxide nanoparticles and its application to glucose detection. Biomaterials 30(27):4716-4722. https://doi. org/10.1016/j.biomaterials.2009.05.005

Zhao JDW, Zhang X, Chai H, Huang Y (2018) FeNPs@Co3O4 hollow nanocages hybrids as effective peroxidase mimics for glucose biosensing. Sens Actuators B 263:575-584. https://doi. org/10.1016/j.snb.2018.02.151

Zheng X, Liu Q, Jing C, Li Y, Li D, Luo W, Wen Y, He Y, Huang Q, Long YT, Fan C (2011) Catalytic gold nanoparticles for nanoplasmonic detection of DNA hybridization. Angew Chem Int Ed Engl 50(50):11994-11998. https://doi.org/10.1002/ anie. 201105121

Zheng XC, Ren W, Zhang S, Zhong T, Duan XC, Yin YF, Xu MQ, Hao YL, Li ZT, Li H, Liu M, Li ZY, Zhang X (2018) The theranostic efficiency of tumor-specific, pH-responsive, peptide-modified, liposome-containing paclitaxel and superparamagnetic iron oxide nanoparticles. Int J Nanomed 13:1495-1504. https://doi. org/10.2147/IJN.S157082

Zhou Z, Sun Y, Shen J, Wei J, Yu C, Kong B, Liu W, Yang H, Yang S, Wang W (2014) Iron/iron oxide core/shell nanoparticles for magnetic targeting MRI and near-infrared photothermal therapy. Biomaterials 35(26):7470-7478. https://doi.org/10.1016/j.bioma terials.2014.04.063 